ISSN: 0514-7336

DOI: http://dx.doi.org/10.14201/zephyrus201372113138

\title{
EL TRABAJO ARTESANAL EN AUGUSTA EMERITA DURANTE LOS SS. I-IV d. C.
}

\section{The artisan work in Augusta Emerita during the II ${ }^{\text {nd }}$ to $I^{\text {th }}$ century $A D$}

\author{
Macarena Bustamante Álvarez \\ Instituto de Arqueología de Mérida, CSIC. Correo-e: macarena.bustamante@iam.csic.es
}

Recepción: 07/06/2012; Revisión: 12/09/2012; Aceptación: 31/10/2012

BIBLID [0514-7336 (2013) LXXII, julio-diciembre; 113-138]

RESUMEN: Actualmente en la antigua capital lusitana es posible examinar, además de los restos arquitectónicos de sus edificios públicos y de una espléndida musivaria en ámbito doméstico, los indicios de otras producciones locales a las que hasta ahora no se les había concedido más que un interés de tipo secundario.

En el presente trabajo damos a conocer una síntesis de las evidencias arqueológicas existentes del artesanado emeritense durante los ss. I-IV d. C. Este tema había sido revisado de manera aislada y esporádica en este solar. Aquí se valoran las estructuras, modos productivos y posibles evidencias de la mano de obra usada. Las constantes excavaciones que se han desarrollado en las últimas décadas han sacado a la luz 33 hornos cerámicos, 2 molinos alimentarios, 7 fullonicae, 1 officina infectae, 4 talleres de vidrio, 1 lanifricaria, 2 talleres de hueso, 2 pistrinae, 2 hornos metalúrgicos y 3 caleras que permiten el desarrollo de estudios de cierta envergadura. La industrial textil, la alfarera, alimentaria o metalúrgica, entre otras, son analizadas arqueológicamente. A partir de ello ha sido posible establecer un mapa de distribución de las distintas áreas manufactureras y de sus posibles zonas de influencia.

Palabras clave: Manufacturas romanas. Lusitania. Análisis topográfico. Evidencias arqueológicas. Talleres locales.

ABSTRACT: Nowadays in the ancient Lusitanian capital it is possible to examine, besides the architectural remains of his public buildings and a set of a splendid mosaics in domestic areas, the evidences of other local productions to which till now it had not been granted to them any interest. In the present work we announce a synthesis of the archaeological existing evidences of the Emeritan craft during the ss. I-IV AD. This theme had been checked in an isolated and sporadic way. Here we value the structures, productive manners and possible evidences of the workforce. The constant excavations developed in the last decades have extracted to the light 33 ceramic ovens, 2 food mills, 7 fullonicae, 1 officina infectae, 4 glass workshops, 1 lanifricaria, 2 workshops of bone, 2 pistrinae, 2 metallurgical furnaces and 3 lime furnaces that allow the development of studies of certain importance. The textile industry, ceramic, nutritious or metallurgical are analyzed from a point of archaeologic view. Since then it has been possible to establish a distribution map of the different manufacturing areas and of its possible zones of influence.

Key words: Roman crafts. Lusitania. Topographical analysis. Archeological evidences. Local workshop. 


\section{Introducción}

El estudio del trabajo en la Antigüedad es un tema conocido y bien sistematizado para algunos puntos del imperio. Ejemplo de ello son las investigaciones que se vienen desarrollando en el ámbito vesubiano o en la Gallia (Brun, 2009; Monteix y Tran, 2011). Por el contrario, otros espacios geográficos no gozan de esta situación, bien por las condiciones de conservación o bien porque las investigaciones se han centrado en otros aspectos. Podemos decir que el artesanado emeritense ha sido uno de los puntos olvidados en la historiografía, pero, sin lugar a dudas, es un campo abierto para la investigación futura.

Con este trabajo queremos rastrear los indicios existentes sobre el entramado artesanal emeritense tras la primera aproximación de Alba (2012). Partimos de la base de que Augusta Emerita fue, además de capital administrativa, capital económica de todo su entorno y, por consiguiente, el tejido artesanal urbano y sus instalaciones tuvieron que ser un hito paisajístico común en la capital de la Lusitania.

Pero junto con este carácter cotidiano $\mathrm{y}$, por consiguiente, de continua presencia, queremos constara los inconvenientes que han dificultado este estudio:

- En algunas de estas actividades se procesan y generan productos perecederos, de ahí que no haya quedado constancia de ellos.

- La ocupación diacrónica que ha sufrido la ciudad hasta hoy ha generado la destrucción de muchas de las estructuras vinculadas a estas labores.

- La mayor parte de la actividad arqueológica emeritense se desarrolla por labores de urgencias $\mathrm{y}$, por consiguiente, constreñidas a un espacio físico delimitado.

- La riqueza arqueológica que alberga Mérida ha generado que la historiografía se haya centrado en las "producciones artísticas", quedando estas otras en un nivel secundario.

Consideramos que el trabajo artesanal es la actividad premeditada y desarrollada por una persona o conjunto de ellas que, organizadas o no, a partir de una serie de pasos, puede transformar una materia prima en un producto manufacturado, sin ayuda alguna de maquinaria industrializada y conlleva intrínsecamente, en su mayoría, un valor crematístico.
El grado de conocimiento que tenemos en la actualidad sobre el artesanado emeritense es poco homogéneo y depende de la actividad desarrollada. Las que podemos tratar más ampliamente son la alfarería, la panificación y el trabajo de los textiles; sin embargo, hay otras que, aunque se desarrollaron ampliamente en la ciudad, la única evidencia que tenemos es su resultado final, es decir, el producto y no las instalaciones.

\section{La producción cerámica}

La actividad artesanal emeritense por antonomasia fue la alfarera. Son muchos los hornos hasta ahora localizados, casi cuarenta agrupados en unos veinte talleres. La ubicación de estos talleres se presenta muy constante: en las afueras de la ciudad siguiendo las normativas recogidas en la Lex Ursonensis.

La localización de estas figlinae está íntimamente relacionada con el propio desarrollo urbanístico. La organización anárquica inicial de los talleres va en sintonía con el propio desarrollo de la ciudad. Los complejos más antiguos, los julio-claudios, se ubican fuera de la ciudad en la margen izquierda del Guadiana -aproximadamente el 22\% de los localizados-. Por el contrario, los talleres de fines del s. I d. C. -más del 50\%- aparecen en el sureste de la colonia en un posicionamiento favorable a los vientos (Fig. 1).

En los primeros momentos de vida de la colonia, las labores administrativas estarían más centradas y volcadas en el propio corazón del municipio. Los espacios públicos forenses son los focos de atención de esta urbanización inicial. Las tempranas instalaciones alfareras se desarrollan ajenas a esta planificación, al menos, hasta mediados del $s$. I d. C. En estos momentos el centro productivo se concentra en la zona sur, en un espacio más alejado del núcleo poblacional y donde la polución generada saliera directamente al ager.

Estos talleres se presentan como entidades autónomas entre ellas contando con todos los medios de producción en su espacio ${ }^{1}$. Fosas de extracción de

${ }^{1}$ La superposición urbanística que se ha producido en Mérida es el motivo fundamental de que los complejos excavados no se hayan estudiado en su extensión originaria, ya que las excavaciones están constreñidas a actuaciones parcelarias actuales. 
arcilla, cisternas, piletas de decantación, estructuras de combustión o testares suelen aparecen en un entorno inmediato, logrando así un abaratamiento extremo de costes.

Las fosas de extracción de arcilla presentan un esquema reiterativo, oval y geminado, cuya fisonomía responde a una cuestión práctica, generando un espacio más amplio que facilitara la extracción completa por vetas. El uso de materia prima cercana a los focos productivos se ha podido comprobar también mediante la caracterización mineralógico-petrográfica. La aplicación de

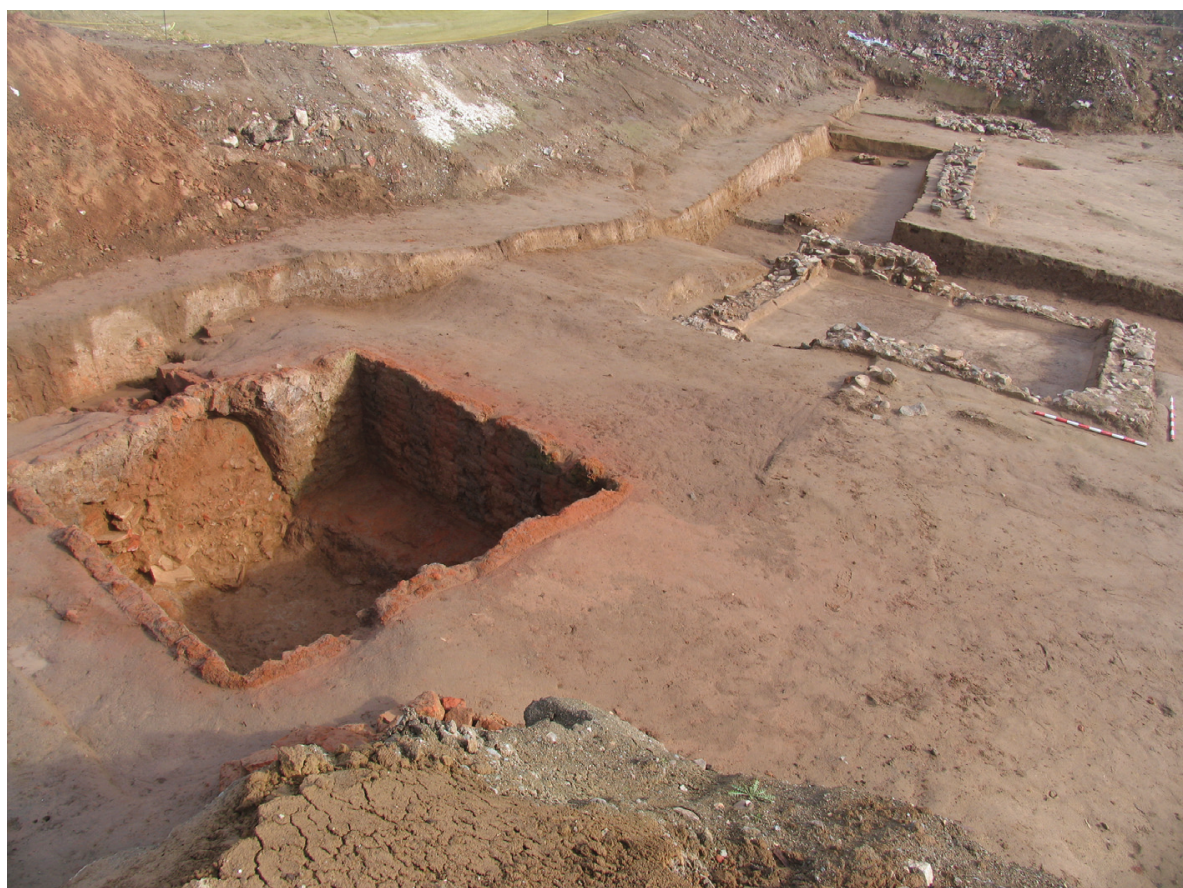

FIG. 1. Vista del complejo alfarero de la Escuela de Hostelería (fotografía de F. J. Heras). distintas técnicas arqueométricas nos permite hablar de una naturaleza granodiorítica de las pastas, con aportes metamórficos, arrastrados por el curso del Guadiana y en perfecta sintonía con el entorno geológico de la zona (Estévez, 1998: 71).

La captación de aguas se produce por tres vías: los cursos fluviales del Anas y del Barraeca, el afloramiento natural y su estancamiento natural mediante cisternas.

En cuanto a los hornos, los localizados hasta el momento presentan una amplia diversidad de tipos que responde a distintas tradiciones culturales de la zona, pero sobre todo a cuestiones de pragmatismo. El esquema constructivo de estas estructuras es muy reiterativo. En primer lugar, se excava una amplia zanja de construcción que presenta dimensiones más amplias que la propia estructura y que, además de facilitar su construcción, favorece su dilatación ante fuertes contrastes térmicos. Estas fosas suelen presentar un perfil cuadrangular con una pequeña oquedad central que se adereza con una cama de piedras dioríticas que favorecería una preservación mayor de la temperatura adquirida. En segundo lugar, se construye la subestructura del horno, es decir, la caldera.
La técnica utilizada hace uso de adobes trabados con arcilla. En tercer lugar, se rellena la fosa del horno con pellas de arcilla; el carácter expansivo de la arcilla es el motivo principal por el que constituye esta el relleno ideal. En cuarto lugar, se construye la parrilla con adobes muy rubefactados y horadada para facilitar el irradiado del calor. En otras ocasiones también se recurre al uso de las toberas. En Mérida, únicamente se han localizado ejemplos de toberas en el testar de la c/ Constantino, que es un complejo muy focalizado en la producción de vajilla fina. Para finalizar, se construye el laboratorio de la estructura por medio de adobes, tapial y ladrillos a modo de cúpula o falsa cúpula. En algunos hornos, tras todo esto, se observa un repellado externo con arcilla muy líquida, quizás para concederle una homogeneidad externa a la estructura.

La morfología de plantas de estos hornos es común y muy reiterativa: predomina la planta cuadrada $-71,05 \%$ - frente a la planta circular -18,41\%-. Entre los de planta cuadrangular encontramos principalmente los tipos Cuomo II/a y II/b y los circulares responden a los tipos Cuomo I/b y I/d. Además, es posible observar 
también cómo las estructuras ovaladas son las más tardías.

La organización espacial de los alfares es bastante anárquica presentándose en ocasiones un espacio central sobre el cual vierten los praefurnia de los hornos del complejo. La gestión de los residuos generados suele estar bien articulada. Se observa un constante reaprovechamiento del espacio (Acero, 2011: 173-174). Así, las limpiezas de las cargas de los praefurnia de los hornos o los materiales defectuosos suelen volver a su origen, a las fosas de extracción de arcillas; en otras, se reutilizan en las propias estructuras del taller. Esto genera un reciclado extremo dentro de estos complejos tanto espacial -reaprovechando las fosas excavadas en el suelo- como material -usando los defectos de cocción como material constructivo-.

En cuanto a la organización humana, son muy pocos los datos con los que contamos pero, a priori, estamos ante mano de obra libre como podemos deducir del análisis de algunos sigilla de piezas claramente locales. Así, en las lucernas con acabados locales irisados, los tria nomina abundan. Se destacan los alfareros PIL, C.L., ETF o INTIF, en época de Claudio. Posteriormente, en los últimos decenios del s. I d. C., se localizan piezas selladas por los artesanos Ges, Gabinia y C.Oppi.Res ${ }^{2}$ (Rodríguez, 2002). Tampoco descartamos el uso de mano femenina e infantil en el proceso manufacturero de algunas piezas de mayor precisión, caso de las terracotas o las lucernas, donde las huellas dactilares que se aprecian son sensiblemente inferiores a las masculinas. Esto tendría sentido si tenemos en cuenta que el amasado y pegado de las valvas de estos productos es una labor muy meticulosa y requiere de gran precisión, por lo que dactilares más amplios dificultarían el fino acabado de estos productos (Fig. 2).

Los hornos más antiguos en la ciudad remontan a los primeros momentos de la colonia (Bustamante y Heras, 2013) manteniéndose la actividad alfarera hasta la mitad de la centuria pasada. Para época romana altoimperial la gran eclosión se centra

${ }^{2}$ A día de hoy desconocemos si hablamos de alfareros locales o si por el contrario estamos ante la imitación genérica de vasos a partir de "sobre moldes", copiándose incluso sus firmas.
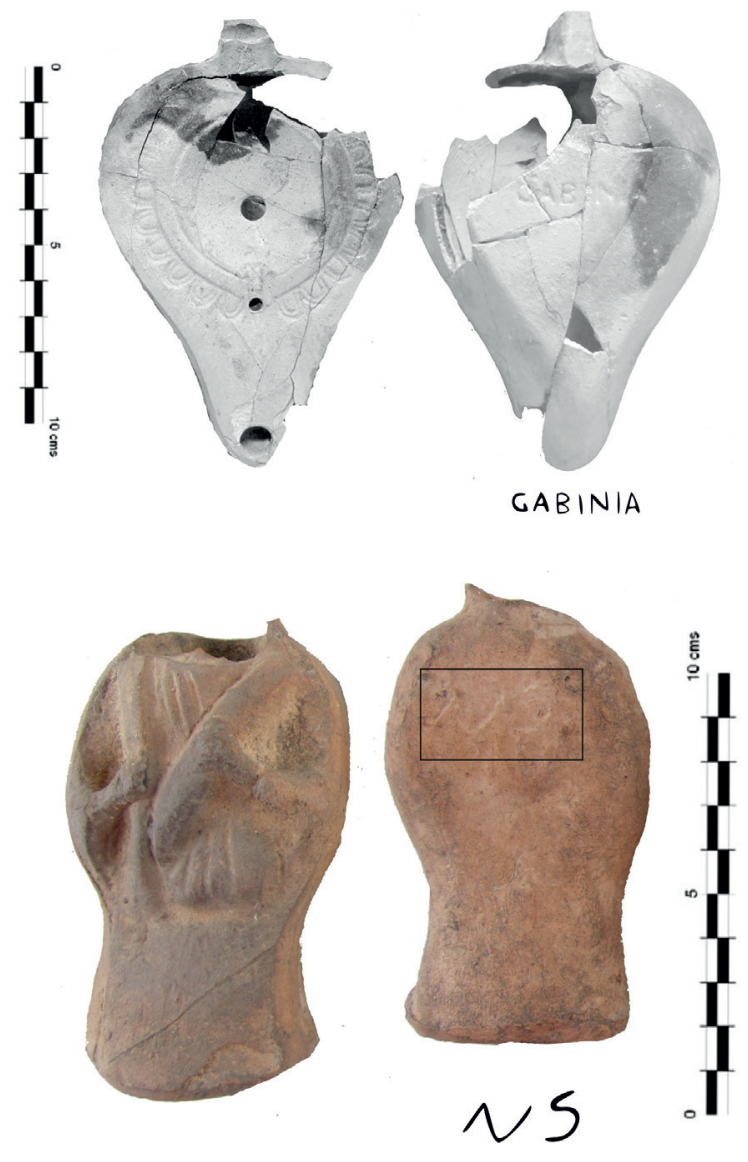

FIG. 2. Vista de sigillum Gabinia sobre lucerna local y marca de alfarero local NS sobre terracota.

en la segunda mitad del s. I d. C. con la apertura de los hornos de paredes finas, el verdadero símbolo de la producción cerámica local, siendo la época de los primeros flavios el clímax.

$\mathrm{Si}$ analizamos espacialmente estos complejos podemos decir que estamos ante una actividad perfectamente organizada y planteada premeditadamente. Las cercanías a los cursos fluviales y a las grandes vías de salida terrestres, caso del puente romano, hacen que valoremos su organización. Recordemos que ésta sería la tónica habitual de los complejos alfareros peninsulares (Juan, 1990). Así, la ubicación en la zona sur permite que la actividad no enturbie el discurrir normal de la vida en la ciudad. Los vientos de la zona arrastrarían los desechos (sobre todo humos y cenizas) hacia el sur, donde el espacio urbano había concluido. Por consiguiente, vemos una organización espacial bien establecida (Fig. 3). 


\begin{tabular}{|c|c|c|c|c|c|}
\hline $\begin{array}{c}\text { Ubicación / } \\
\text { Ref. bibliográfica }\end{array}$ & Horno & Tipo & Otras estructuras & Producción & Cronología \\
\hline C/ San Salvador (Barrantes, 1877) & - & Circular & Estancias & Vajilla fina & altoimperial \\
\hline $\begin{array}{l}\text { Ambulatorio Zona Sur } \\
\text { (Calero, 1986: 92) }\end{array}$ & - & - & - & Vajilla fina, lucernas & - \\
\hline $\begin{array}{l}\text { Zona Tren-Pancaliente } \\
\text { (Calero, 1986: 93) }\end{array}$ & - & - & - & Vajilla fina, lucernas & - \\
\hline $\begin{array}{l}\text { Inmediaciones c/ Oviedo } \\
\text { (citado en Barrientos, 2007, } \\
\text { pero aún inédito) }\end{array}$ & - & Cuadrangular & - & Lucernas & - \\
\hline $\begin{array}{l}\text { Vertederos c/ Constantino } \\
\text { (Rodríguez, 1996; Alvarado y } \\
\text { Molano, 1991) }\end{array}$ & $\begin{array}{r}\text { Piletas y } \\
\text { testares }\end{array}$ & - & Piletas y testares & $\begin{array}{l}\text { Comunes, paredes finas, } \\
\text { lucernas y constructivo }\end{array}$ & 2. ${ }^{\mathrm{a}} 1 / 2$ s. I d. C. \\
\hline Campo de fútbol (Márquez, 1997a) & A7 & Cuomo II /b & Pozos y piletas & \begin{tabular}{|l|}
$\begin{array}{l}\text { Material constructivo } \\
\text { (tegulae y testae) }\end{array}$ \\
\end{tabular} & 1. a $1 / 2$ s. I d. C. \\
\hline \multirow{3}{*}{$\begin{array}{l}\text { Camino del Peral, s/n } \\
\text { (Alba, Márquez y Saquete, 1997) }\end{array}$} & $\begin{array}{l}\text { UU EE } \\
30-40\end{array}$ & Cuomo II /b & $\begin{array}{c}\text { Estructuras } \\
\text { pavimentadas con } \\
\text { signinum } \\
\end{array}$ & $\begin{array}{l}\text { Material constructivo } \\
\text { (tegulae y testae) }\end{array}$ & 1/2 s. I d. C. \\
\hline & $\begin{array}{l}\text { UU EE } \\
50-51\end{array}$ & $\begin{array}{c}\text { Planta cuadrangular } \\
\text { arrasada }\end{array}$ & $\begin{array}{c}\text { Estructuras } \\
\text { pavimentadas con } \\
\text { signinum }\end{array}$ & $\begin{array}{l}\text { Material constructivo } \\
\text { (tegulae, testae e imbrices) }\end{array}$ & 1. a $1 / 2$ s. I d. C. \\
\hline & $\begin{array}{c}\text { Proxim. } \\
\text { Banco } \\
\text { Banesto }\end{array}$ & - & $\begin{array}{c}\text { Estructuras } \\
\text { pavimentadas con } \\
\text { signinum } \\
\end{array}$ & - & - \\
\hline C/ Anas (Sánchez y Alba, 1998a) & $\mathrm{A} 1$ & Cuomo II /b & $\begin{array}{c}\text { Balsas de } \\
\text { decantación y } \\
\text { posible embalse } \\
\end{array}$ & $\begin{array}{l}\text { Material constructivo } \\
\text { (tegulae, testae e imbrices) }\end{array}$ & 1. ${ }^{\mathrm{a}} 1 / 2 \mathrm{~s}$. I d. C. \\
\hline \multirow{5}{*}{$\begin{array}{l}\text { Bodegones } \\
\text { (Sánchez y Alba, 1998b) }\end{array}$} & A1 & Cuomo II /b & Piletas & $\begin{array}{l}\text { Material constructivo } \\
\text { (tegulae, testae e imbrices) }\end{array}$ & 1. a $1 / 2$ s. I d. C. \\
\hline & A2 & Cuomo II /b & Piletas & $\begin{array}{l}\text { Material constructivo } \\
\text { (tegulae, testae, imbrices, } \\
\text { baldosas y piezas de columnas) }\end{array}$ & 1. a $1 / 2$ s. I d. C. \\
\hline & A3 & Cuomo II /b & Piletas & \begin{tabular}{|l} 
Material constructivo \\
(tegulae, testae, imbrices, \\
baldosas y piezas de columnas) \\
\end{tabular} & 1. a $1 / 2$ s. I d. C. \\
\hline & A4 & Cuomo II /b & Piletas & $\begin{array}{l}\text { Material constructivo } \\
\text { (tegulae, testae, imbrices, } \\
\text { baldosas y piezas de columnas) }\end{array}$ & 1. a $1 / 2$ s. I d. C. \\
\hline & A5 & Cuomo II /b & Piletas & $\begin{array}{l}\text { Material constructivo } \\
\text { (tegulae, testae, imbrices, } \\
\text { baldosas y piezas de columnas) } \\
\end{array}$ & 1. a $1 / 2$ s. I d. C. \\
\hline $\begin{array}{l}\text { Polígono "El Prado" } \\
\text { (Bejarano, 2000) }\end{array}$ & $\mathrm{A} 2$ & Cuomo II /b & $\begin{array}{c}\text { Estructuras } \\
\text { pavimentadas con } \\
\text { signinum } \\
\end{array}$ & $\begin{array}{l}\text { Material constructivo } \\
\text { (testae, tegulae e imbrices) }\end{array}$ & ss. I-II d. C. \\
\hline C/ Muza (Silva y Sánchez, 2001) & - & - & $\begin{array}{l}\text { Estructuras con } \\
\text { signinum y noria }\end{array}$ & Materiales constructivos & ss. I-II d. C. \\
\hline \multirow{2}{*}{$\begin{array}{l}\text { Las Rozas } \\
\text { (Nodar y Olmedo, 2004) }\end{array}$} & A2 & Cuomo II /c & Balsas y estructuras & $\begin{array}{l}\text { Material constructivo } \\
\text { (imbrices, tegulae y casetones } \\
\text { de columnas) }\end{array}$ & ss. II-III d. C. \\
\hline & $\mathrm{A} 3$ & Cuomo II /b & Balsas y estructuras & Materiales constructivos & ss. I-II d. C. \\
\hline \multirow{4}{*}{$\begin{array}{l}\text { Avda. Lusitania - } \\
\text { C/ Dámaso Alonso } \\
\text { (Méndez y Alba, 2004) }\end{array}$} & A7 & Cuomo I/b & Pozos y piletas & Cerámica común & ss. I-II d. C. \\
\hline & A8 & Cuomo I/d & Pozos y piletas & Cerámica común & ss. I-II d. C. \\
\hline & A9 & Cuomo II /b & Pozos y piletas & $\begin{array}{l}\text { Cerámica común y material } \\
\text { constructivo }\end{array}$ & ss. I-II d. C. \\
\hline & A10 & Cuomo II /a & Pozos y piletas & Cerámica común & ss. I-II d. C. \\
\hline
\end{tabular}

FIG. 3. Cuadro sinopsis de los talleres alfareros localizados en Mérida. 


\begin{tabular}{|c|c|c|c|c|c|}
\hline $\begin{array}{c}\text { Ubicación / } \\
\text { Ref. bibliográfica }\end{array}$ & Horno & Tipo & Otras estructuras & Producción & Cronología \\
\hline $\begin{array}{l}\text { C/ Augusto, } 44 \\
\text { (Palma, 2004) }\end{array}$ & $\mathrm{A} 1$ & $\begin{array}{c}\text { Planta cuadrangular } \\
\text { parcialmente } \\
\text { excavada }\end{array}$ & $\begin{array}{l}\text { Estructuras y } \\
\text { pavimentos de } \\
\text { signinum }\end{array}$ & Tegulae & ss. I-II d. C. \\
\hline \multirow{6}{*}{$\begin{array}{l}\text { Avda. Lusitania } \\
\text { (Alba y Méndez, 2005) }\end{array}$} & A18 & Cuomo II /b & Pozos y piletas & Cerámicas comunes & ss. I-II d. C. \\
\hline & A19 & Cuomo II /b & Pozos y piletas & $\begin{array}{l}\text { Cerámicas comunes, tegulae, } \\
\text { imbrices, y pesas de telar }\end{array}$ & ss. I-II d. C. \\
\hline & $\mathrm{A} 20$ & Cuomo I/d & Pozos y piletas & Cerámicas comunes & ss. I-II d. C. \\
\hline & A21 & Cuomo I/d & Pozos y piletas & Cerámicas comunes & ss. I-II d. C. \\
\hline & A22 & Cuomo I/d & Pozos y piletas & Cerámicas comunes & ss. I-II d. C. \\
\hline & A26 & Cuomo II /d & Pozos y piletas & Cerámicas comunes & ss. I-II d. C. \\
\hline \multirow{4}{*}{ C/ Concejo, 19 (Barrientos, 2007) } & A56 & Coll 7/a & - & $\begin{array}{l}\text { Paredes finas, lucernas y } \\
\text { comunes }\end{array}$ & 2. a $1 / 2$ s. I d. C. \\
\hline & A 52 & Cuomo II /b & - & $\begin{array}{l}\text { ¿Paredes finas?, lucernas y } \\
\text { comunes }\end{array}$ & 2. ${ }^{\mathrm{a}} 1 / 2 \mathrm{~s}$ s. I d. C. \\
\hline & A57 & $\begin{array}{c}\text { Planta cuadrangular } \\
\text { parcialmente } \\
\text { excavada } \\
\end{array}$ & - & 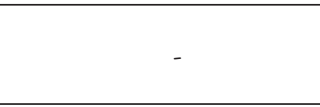 & 2. a $1 / 2$ s. I d. C. \\
\hline & A51 & Cuomo I/b & - & $\begin{array}{l}\text { Paredes finas, lucernas y } \\
\text { comunes }\end{array}$ & 2. ${ }^{\mathrm{a}} 1 / 2 \mathrm{~s}$ s. I d. C. \\
\hline \multirow{2}{*}{ Solar Campsa (2007) } & - & Cuomo II /b & Testar & Cerámicas comunes & 2. a $1 / 2$ s. I d. C. \\
\hline & - & Cuomo II /b & Testar & Cerámicas comunes & 2. a $1 / 2$ s. I d. C. \\
\hline \multirow{2}{*}{$\begin{array}{l}\text { Escuela de Hostelería } \\
\text { (Bustamante y Heras, 2013) }\end{array}$} & - & Cuomo II/b & Pozo y pileta & Ánforas y constructivo & 1. a $1 / 2$ s. I d. C. \\
\hline & - & Cuomo II /b & Pozo y Pileta & Ánforas y constructivo & 1. a $1 / 2$ s. I d. C. \\
\hline Ortega Blanco, inédito & - & Cuomo II /b & - & Tegulae & 1/2 s. I d. C. \\
\hline
\end{tabular}

FIG. 3. Cuadro sinopsis de los talleres alfareros localizados en Mérida (cont.).

\section{La panificación en Mérida, evidencias de un producto efímero}

La panadería romana no ha sido objeto de estudio profundo en Hispania. Creemos que esta falta de interés viene dada por su carácter doméstico-cotidiano $y$, por consiguiente, de reducido impacto en la economía local. Sin embargo, el pan en la Antigüedad se convirtió en un producto de primera necesidad (Cerchiai, 2004: 103-104), de ahí que en la fisonomía urbana los lugares de producción fueran hitos comunes.

En Mérida, podemos rastrear esta actividad a partir de tres elementos: las instalaciones en sí, los aperos usados y la iconografía.

\subsection{Las instalaciones vinculadas a la panificación}

Vamos a comenzar con las estructuras. En Mérida se ha localizado una de las instalaciones hispanas más claras 3 ; sita en la cl Almendralejo, 41, consta de las partes más importantes en el proceso de panificación -horno, zona de amasado y zona de almacenamiento de grano-.

De igual modo, se puede deducir, por paralelos morfológicos, otro pistrinum en la ribera este del Guadiana (Mélida y Macías, 1929: 34-35)4. Allí se localizó un conjunto de dolia con decoración acordonada y dispuestos de manera distal, de forma similar al de la c/ Almendralejo, 41. En el centro

\footnotetext{
${ }^{3}$ Agradezco los datos aportados por C. Pérez Maestro y quiero indicar que la misma se encuentra en curso de estudio, entre otros, por la firmante de este trabajo (permiso n. ${ }^{\circ}$ 34/2012).

${ }^{4}$ Los autores hablan de una posible cronología medieval a tenor del uso de la cerámica con decoración acordonada. A pesar de ello, cuando se analiza la imagen reproducida (lám. XXI) parece posible fechar la instalación en pleno s. VI d. C. si comparamos la factura de estos dolia con otros localizados en suelo emeritense, como, por ejemplo, los del pistrinum de la c/ Almendralejo, 41.
} 
de la estancia apareció un pozo circular, elemento necesario para el procesado del pan. A pesar de todos los elementos descritos, en un principio se definió como almazara, interpretación que no consideramos adecuada. En este sentido la necesidad de abastecimiento constante de materia prima, en este caso aceitunas, harían que la ubicación más idónea fuera en el territorium emeritense, como se viene atestiguando en todo el rosario de villae localizadas.

Además de esto se ha localizado un posible molino hidráulico en el entorno de Pancaliente, en la margen derecha del Guadiana (Estévez, 2001; Alba, 2012: 356) que podría haber cristalizado en su topónimo actual y en la actividad continuada hasta momentos recientes.

\subsection{Los aperos de panaderos}

El segundo elemento para tratar esta manufactura serían los
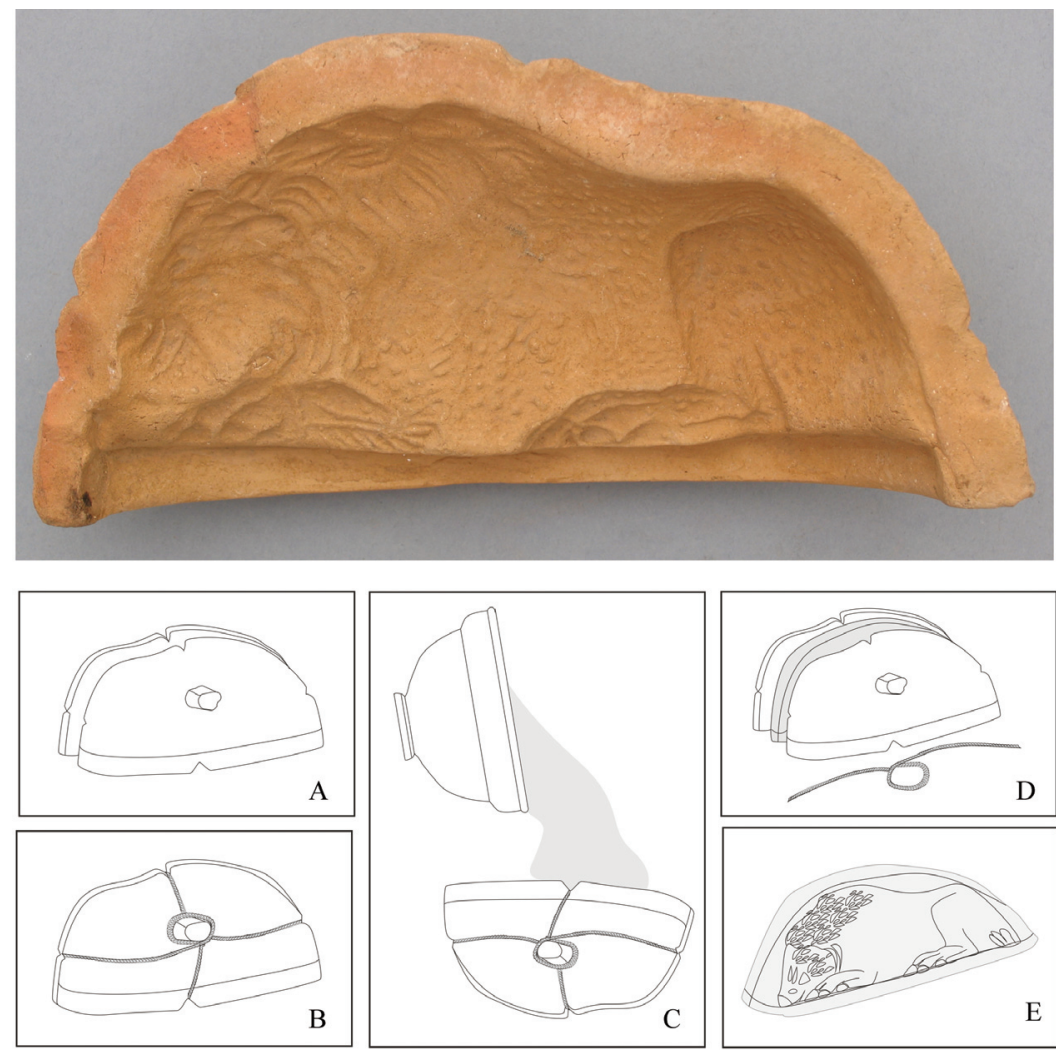

FIG. 4. Kuchenformen localizado en cl Almendralejo, 41 y posible reconstrucción de su uso (a partir de Excoffon y Lemoine, 2008). aperos localizados. Hasta el momento, hemos hallado tres elementos que nos permiten rastrear esta producción en Mérida (Figs. 4 y 5):

- Los sellos de panaderos: son pequeñas matrices circulares realizadas en terracota que permitirían dejar impreso algún motivo sobre los panes. En Mérida se han localizado dos ejemplares, uno con la representación de Júpiter $y$ otro con Ceres que han sido interpretados como matrices para panecillos a ingerir en festividades vinculadas con los ciclos agrícolas (Gijón y Bustamante, 2010).

- Los moldes de pasteleros/ kuchenformen: moldes en bulto redondo realizados en terracota y con unos rasgos morfológicos muy concretos necesarios para el desmolde de estas piezas. En

Mérida hemos localizado tres moldes que representan animales, más concretamente un felino y ovicápridos (Bustamante y Gijón, 2011; Bustamante, Gijón y Olmedo, 2011). Estas piezas han sido interpretadas como matrices para elaborar

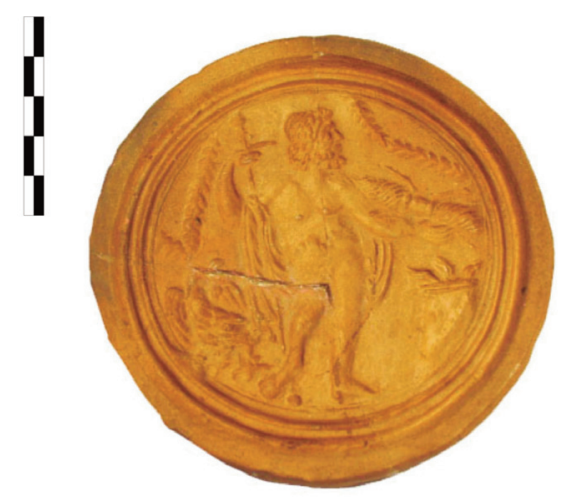

FIG. 5. Sello de panadero localizado en Mérida (Gijón y Bustamante, 2010). 
alimentos que serían repartidos en espectáculos lúdicos, tanto por su iconografía como por paralelos aparecidos directamente en otros pistrina como los de Ostia.

- Los molinos: son los aperos más comunes localizados en Mérida y sobresalen los típicos rotatorios que tienen fuertes reminiscencias de los prehistóricos. Los molinos documentados presentan dimensiones estándares en las que las metae oscilan entre $5,5 \mathrm{~cm}$ y $23 \mathrm{~cm}$. Todos ellos tienen un orificio cilíndrico central de unos $5-10 \mathrm{~cm}$ que horada toda la pieza y que albergaría el eje de rotación. Su parte activa se presenta de manera inclinada siendo la zona central más alta que la externa, permitiendo que el producto molido caiga al exterior. El catillus o parte rotatoria, también circular, presenta las mismas dimensiones a excepción del orificio central más amplio para facilitar que el grano caiga sobre la parte fija. Su posicionamiento es inverso a la parte inferior siendo la zona más alta la distal, lo que permite un mejor descenso del producto. Uno de sus laterales aparecería perforado para insertar la manivela de rotación realizada en material perecedero -posiblemente lígneo-, debido a su ausencia en los ejemplares localizados.

Dentro de este grupo existe una máquina de uso específico para la panificación, las amasadoras/pétrins que facilitan el trabajo y el modelado de las masas. Estos instrumentos están conformados por varias piezas. En primer lugar, un cilindro pétreo horadado en la zona media donde se ubicaría un eje central; este eje estaría realizado en metal y en madera y cuya rotación accionaría un brazo metálico plano, el verdadero amasador. Todo ello quedaría precintado por unos topes superiores lígneos que evitarían que la pasta se vertiera. En Pompeya se han localizado abundantes ejemplos en espacios claramente vinculados con la panificación, caso del ejemplo de la insula de los "Castos Amantes" (IX, 12, 6). Para Hispania uno de los únicos ejemplos claros se ha localizado en Mérida, en la Casa del Anfiteatro. Allí, en la denominada estancia 5, asociada a una cocina doméstica (Pizzo, 2004: fig. 5), se conserva una amasadora, más concretamente el cilindro externo, que ha pasado desapercibido como un simple molino; de hecho, en la actualidad se ubica "abrazando" un molino rotatorio manual. En las proximidades de este ejemplo se localiza un pequeño horno que podría haber servido para estos menesteres.

Estas evidencias, en un contexto claramente doméstico, nos permiten aclarar la incógnita de por qué en un espacio tan importante como en Mérida no se conocen estructuras vinculadas a la panificación en época altoimperial. Apostamos, por lo tanto, por un proceso de manufactura altamente doméstico, siendo el caso de la Casa del Anfiteatro claro ejemplo.

\section{Los trabajos textiles: batanares, tintorerías, lanerías y curtidurías}

Frente a la creencia generalizada de que las lavanderías, tintorerías, lanerías y curtidurías estuvieran en íntima relación espacial, incluso albergándose en los mismos espacios, la realidad que nos revela el entorno vesubiano (Médard, Borgard y Moulhérat, 2011) es bien distinta. De igual modo, la constante vinculación que se ha establecido entre estos espacios y la producción artesanal es otro hecho erróneo; la razón estriba en que en estos lugares no se procesa la materia prima hasta convertirla en un elemento manufacturado.

Para analizar este apartado lo dividiremos en dos puntos: la producción y la conservación de pañería.

\subsection{La producción de manufacturas textiles}

En primer lugar efectuaremos una valoración de espacios que, vinculados con la pañería, generen un producto o subproducto a partir de una materia prima (Fig. 6).

\begin{tabular}{|l|c|}
\hline \multicolumn{1}{|c|}{ Ubicación } & Interpretación \\
\hline C/ Almendralejo, 58-60 & Officina lanifricaria \\
\hline $\begin{array}{l}\text { Ribera del Guadiana (Edif. A), } \\
\text { según grabado de F. Rodríguez }\end{array}$ & Officina infectaria \\
\hline $\begin{array}{l}\text { Ribera del Guadiana (Edif. B), } \\
\text { según grabado de F. Rodríguez }\end{array}$ & Fullonica \\
\hline C/ Calvario, 59 & Fullonica \\
\hline C/ Forner y Segarra & Fullonica \\
\hline Alcazaba & Fullonica \\
\hline C/ Marquesa de Pinares & Fullonica \\
\hline Área de servicio del Anfiteatro & Fullonica \\
\hline
\end{tabular}

FIG. 6. Cuadro sinóptico de las instalaciones vinculadas a los textiles localizadas en Mérida. 


\subsubsection{Officinae lanifricariae}

Una de las primeras actividades por la que pasa la lana es el lavado, que se produciría en lo que Moeller (1976) denomina officinae lanifricariae. Estos espacios suelen ser pequeñas instalaciones cuya característica primordial es la existencia de un banco corrido con calderas circulares, equidistantes y empotradas en factura que permitían lavar la lana en repetidas ocasiones y en un ambiente templado (Borgard y Puybaret, 2004: 49-52). De igual modo, es constante la aparición de grandes canales interconectados al aire libre que permiten la constante purificación del agua. Nuevamente recurrimos al caso pompeyano como el ejemplificador ya que nos aporta los datos más fiables al respecto.

La única instalación en Mérida que podemos asociar a una lanifricaria se ubica en la cl Almendralejo, 58-60. En estos solares aparecieron una serie de estructuras claramente artesanales (Alvarado, Molano y Gijón, 1995: 1008). Aunque con reparos por la ubicación en el centro propio del municipio romano, estos autores 5 la plantearon como una fullonica (Fig. 7). De esta instalación únicamente se localizaron dos piletas revestidas con opus signinum y adosadas al muro de cierre de la instalación así como varios canales, algunos de ellos insertos en las mismas cubetas y otros circundando todo el complejo. Ambas balsas muestran morfología -una es rectangular y otra cuadrangular- y dimensiones distintas $-2 \times 3 \mathrm{~m}$ y $3 \times 2 \mathrm{~m}-$. Las dos únicas variables que se repiten son el revestimiento con signinum así como la existencia de canales abiertos y sobreelevados dentro de las piletas. Si cotejamos las plantas con las fullonicae conocidas en Mérida -que luego valoraremos- y con las del ámbito vesubiano no se observa paralelo alguno; sin embargo, cuando rastreamos otros espacios artesanales, las officinae lanifricariae son las más cercanas. El ejemplo más cercano a dichos canales empotrados son los localizados en la officina lanifricaria de la Casa I, 8, 2 de Pompeya, interpretados como elementos para facilitar los continuos lavados por los que pasa la lana (Fig. 8).

\footnotetext{
5 Queremos agradecer los datos aportados a M. E. Gijón Gabriel.
}

En relación con el trabajo de la lana se han localizado en Mérida múltiples utensilios vinculados a la hilandería, elaborados y utilizados en la ciudad. Nos referimos fundamentalmente a los pondera y fusayolas. En las figlinae emeritenses, se ha localizado una gran cantidad de estas piezas, sobre todo pondera, que nos permiten hablar de un cierto autoabastecimiento. Tienen unas medidas, más o menos, estándares entre $9-12 \mathrm{~cm}$ de altura y unos 3-4 cm de grosor. Conocemos en el alfar de la c/ Concejo (Barrientos, 2007) una proliferación de marcas -aspas- en su parte superior y en menor medida en la inferior, que podrían responder a un posible sello de identidad de este taller. En otro taller, el de la avda. Lusitania, se vuelve a localizar la manufactura de estos instrumentos necesarios para la elaboración de tejidos (Alba y Méndez, 2005).

\subsubsection{Officina infectoria}

Con este término nos referimos al lugar destinado a la producción de tintes y su aplicación en la Antigüedad. El término fue acuñado por Moeller (1976) a partir de unas inscripciones electorales (CIL IV, 7812) ubicadas en una de estas instalaciones donde se hacía clara referencia a los infectores.

La única actividad artesanal emeritense referida en las fuentes clásicas -aunque indirectamente- es la de los tintes. Cuando Plinio ( $N$. $H$., IX, 141) analiza los tintes naturales de procedencia animal cita a las cochinillas traídas de Augusta Emerita como las más cotizadas de la Península Ibérica, compitiendo en calidad con las de Galatia que eran las más afamadas del Imperio 6 .

En la actualidad se tiene un conocimiento muy preciso de estas instalaciones, gracias a las labores desarrolladas en ámbito vesubiano -los espacios I, 8, 19; V, 1, 4-5, o la VII, 14, 5 son ejemplos al respecto- (Borgard y Puybaret, 2004).

${ }^{6}$...' coccum Galatiae, rubens granum, ut dicemus in terrestribus, aut circa Emeritam Lusitaniae in maxima laude est est. verum ut simul peragantur nobilia pigmenta, anniculo grano languidus sucus, idem a quadrimo evanidus. ita nec recenti vires neque senescenti. abunde tractata est ratio qua se virorum iuxta feminarumque forma credit amplissimam fier'... 

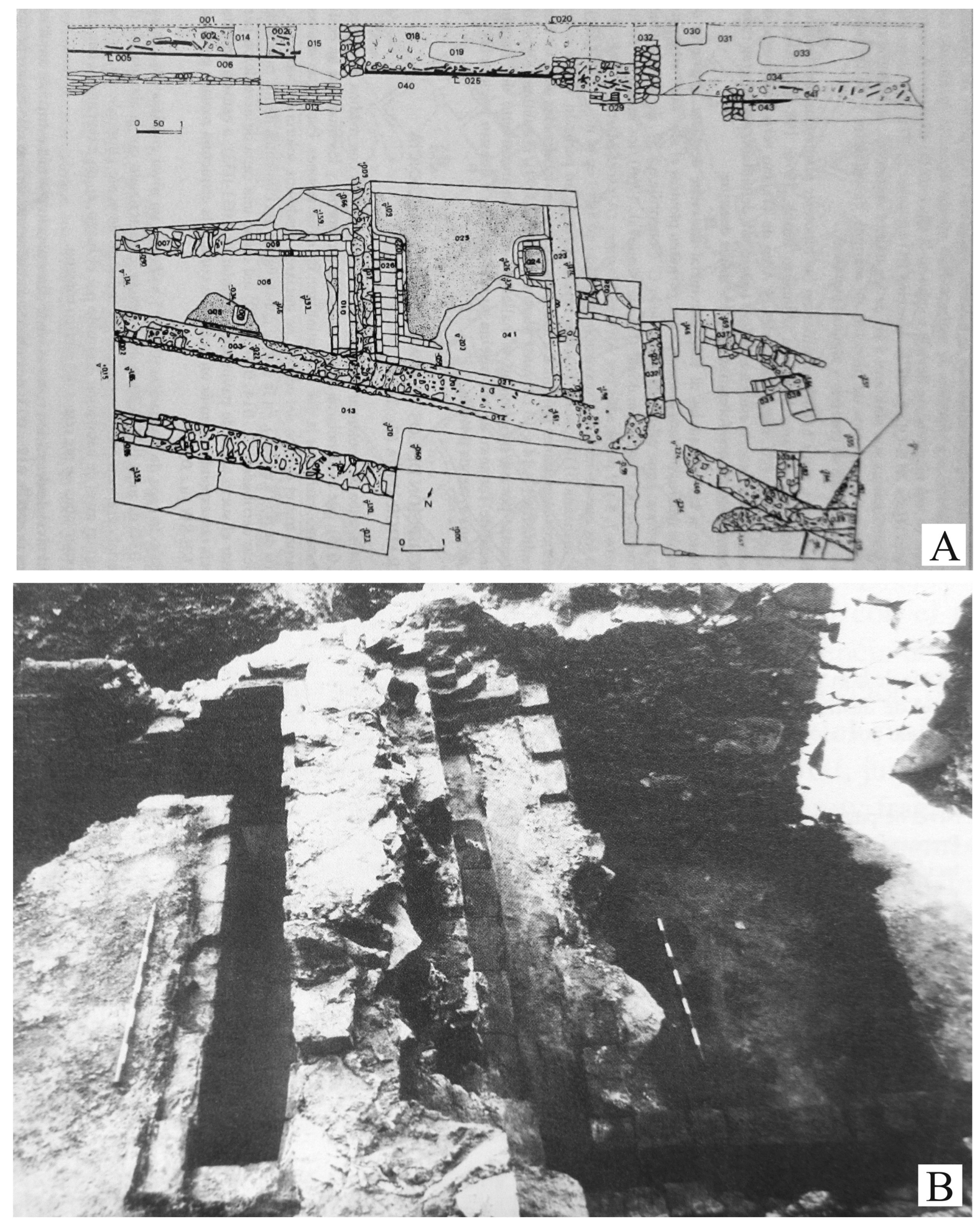

Fig. 7. Planta (A) e imagen (B) de la officina lanifricaria localizada en cl Almendralejo, 58-60 (Alvarado, Molano y Gijón, 1996). 
Uno de los elementos fundamentales para determinar estas instalaciones son unas pequeñas calderas realizadas en mampostería, que permiten procesar la materia prima y hacer el tinte. Su morfología es circular, con unas dimensiones que van entre 0,60 y 1,23 $\mathrm{m}$ y con un desarrollo cilíndrico entre los 40 y $80 \mathrm{~cm}$ de altura. Asímismo existen otros rastreadores, como las ánforas portadoras de alumbre, material usado como conglomerante de los tintes (ibidem).

Para el caso emeritense, las fuentes ponen sobre aviso de la posible existencia de esta actividad, pero los datos arqueológicos que en la actualidad poseemos son pocos y parcos al respecto. La única instalación que a día de hoy asociamos a una officina infectoria es una instalación reproducida en el s. XVIII por el dibujante Fernando Rodríguez ${ }^{7}$ (Arbaiza y Heras, 1998: 325, láms. 13-14; Canto, 2001: 151; Caballero, 2004: 162). Este recoge las plantas de dos edificios a orillas del río Guadiana, sin indicar más precisiones geográ-

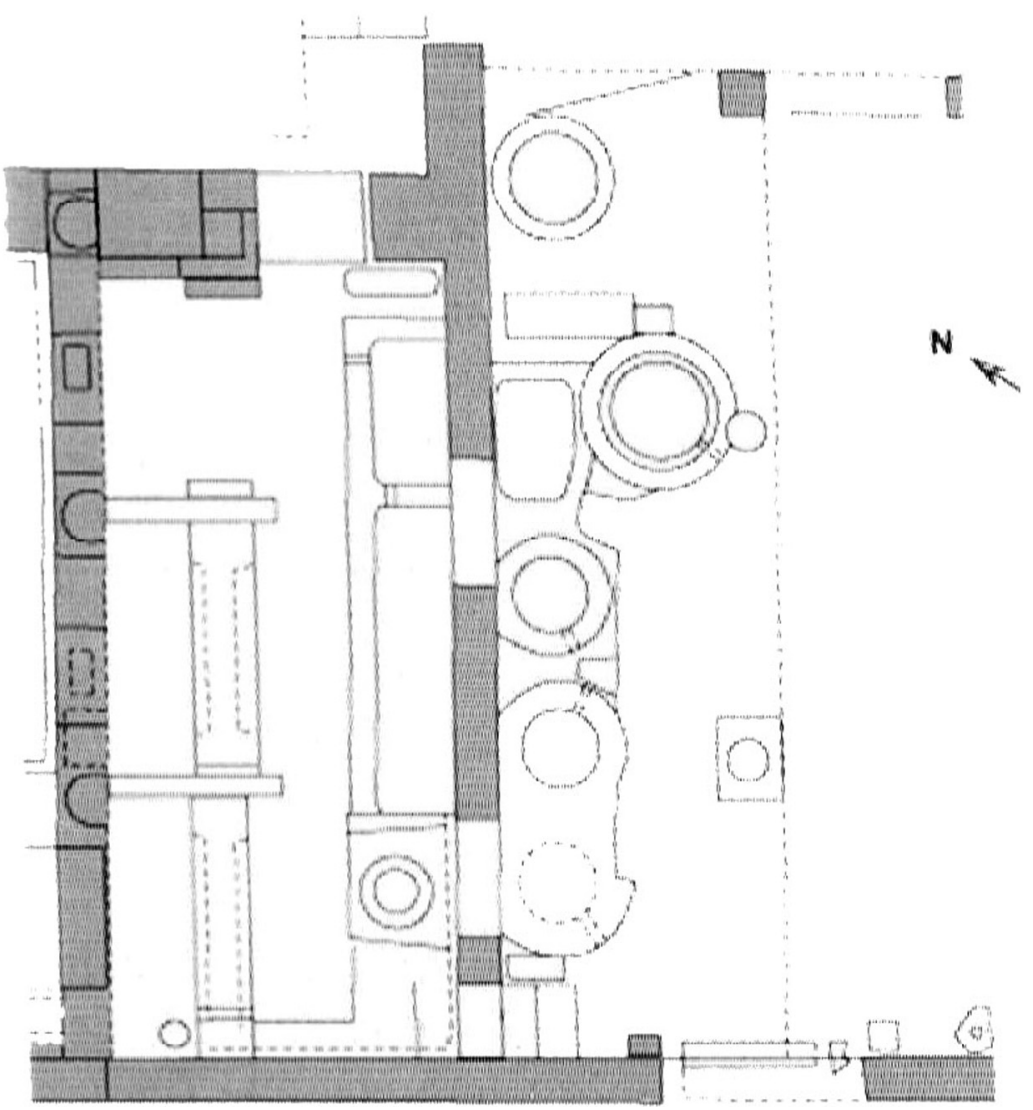

FIG. 8. Planta de la officina lanifricaria de I, 8, 2 Pompeya (Bogard y Puybarte, 2004). ficas al respecto. La leyenda que acompańa el plano se refiere en todo momento a una alfarería - para el edificio de la izquierda- y, en segundo lugar, a una "adovería" -para el edificio de la derecha (sic)-. Sin embargo, cuando nos centramos en el análisis del edificio de la izquierda encontramos una serie de elementos que hacen descartar esa función alfarera inicialmente dada. Centrándonos en la estancia D, donde se ubican los hornos, resulta posible observar los siguientes aspectos (Fig. 9):

1.- La morfología y dimensión de los hornos. Entendemos que la adscripción realizada viene

${ }^{7}$ Grabado n. 3 de F. Rodríguez, firmado el 23 de abril de 1797 y Laborde (1828): "Notice historique sur la ville de Mérida”. En Itinerarie descriptif de l'Espagne. Paris, p. 111. Agradezco los datos y el material gráfico a C. Morán y A. Pizzo.

dada por las trazas de termoalteración dejadas en la superficie inferior de las estructuras, pero cuando se valoran en mayor profundidad, la teoría de los hornos cerámicos se desploma. La planta de estos se presenta totalmente circular, por el contrario los hornos localizados en Mérida muestran una fisonomía bien cuadrada -caso del localizado en la Nave de Azkar (Bejarano, 2000)- o bien en omega -en avda. Lusitania (Alba, 2005)-. La precisión del resto del dibujo nos hace suponer que esta tendencia circular no es fruto de una intención artística sino más bien de una representación directa de la realidad. Si cotejamos la escala representada, las dimensiones de estos rondan los 70$90 \mathrm{~cm}$, por lo que tampoco son más las aptas para que fuesen estas estructuras -recordemos que los hornos de la Escuela de Hostelería tienen unos 


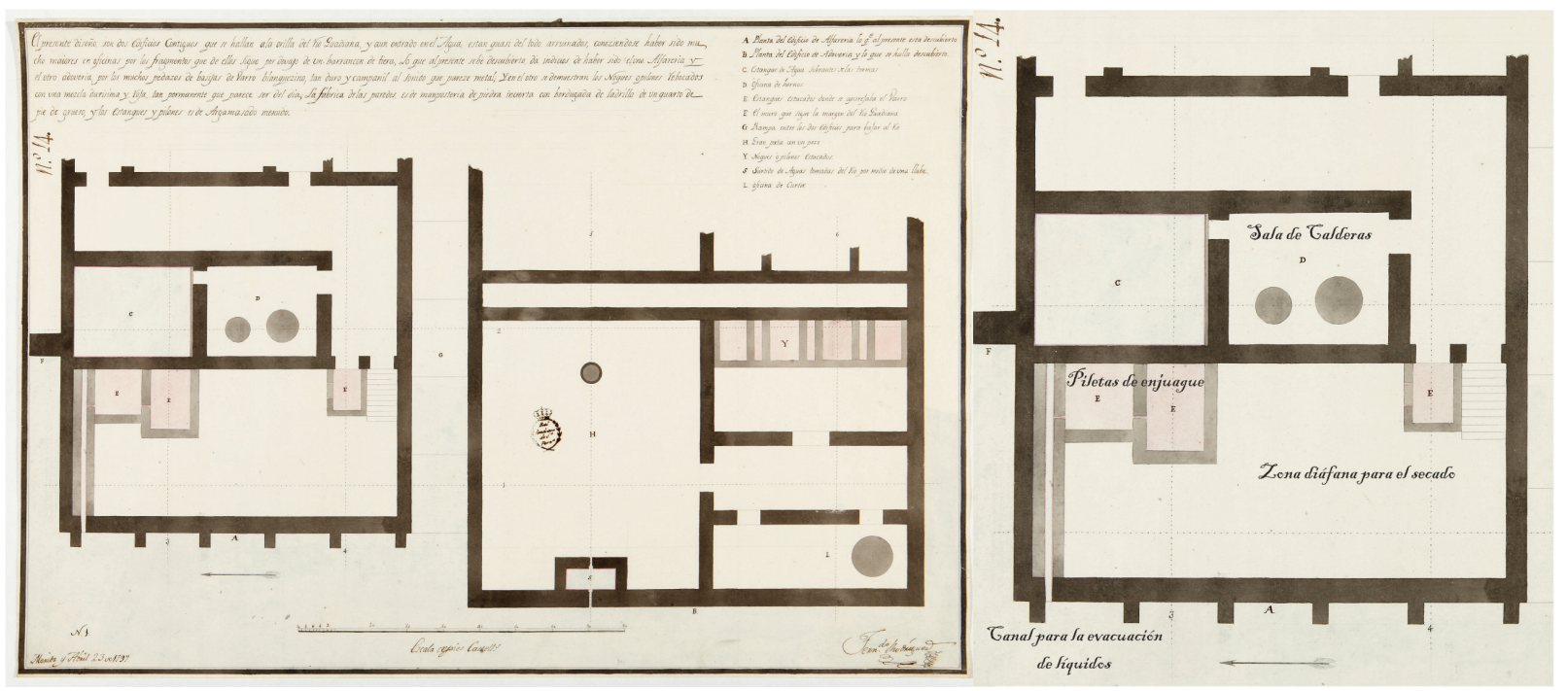

FIG. 9. Planta de la officina infectoria en el edificio A de Fernando Rodríguez y la posible reinterpretación (imagen cortesía de C. Morán y A. Pizzo).

2,70 m-. De igual modo se echa en falta un elemento tan imprescindible para estas estructuras como es el praefurnium.

2.- La ubicación de los hornos. Cuando valoramos la posición respecto a los otros hornos localizados en Mérida observamos que difiere sensiblemente. Las estructuras de combustión de las figlinae suelen aparecen en espacios diáfanos y en ningún momento constreñidos a estancias como es el caso aquí.

Si valoramos otros aspectos, como la aparición de las piletas interconectadas -señalada con la letra E- y con salida directa a la calle por medio de un pequeño canal tampoco cuadra con lo que podemos ver en las figlinae. En este sentido en ninguna de las instalaciones alfareras emeritenses se han localizado piletas conectadas entre sí -pongamos como ejemplo las localizadas en la Nave de Azkar (Bejarano, 2000)-. De hecho, las únicas piletas conexionadas identificadas en Mérida se vienen asociando a fullonicae (Palma, 2001a). De todas formas, si estas piletas hubieran albergado arcilla y su decantación evacuara a la calle por dicho canal, se deduciría su continua obstrucción. Parece pues que este sencillo medio de evacuación sería más útil para productos y subproductos líquidos y no viscosos o semisólidos como la arcilla.

Entonces, ¿ante qué estaríamos? Según nuestra interpretación se trata de un ejemplo claro de una officina infectoria. En primer lugar, el posicionamiento de la instalación a los pies del Guadiana constituye un enclave idóneo para la continua captación de aguas. En segundo lugar, nuestra propuesta se apoya en lo que interpretamos como los restos de dos calderas realizadas en mampostería, puesto que, como ya hemos indicado previamente, su asociación con hornos no parece ser la más exacta. Si las comparamos con las calderas pompeyanas, tanto su morfología - circular- como sus dimensiones $-40 / 60 \mathrm{~cm}-$ coinciden. De hecho, en Pompeya las salas destinadas a las calderas están parcial o totalmente cubiertas como ocurre con nuestra estancia D (Borgard y Puybaret, 2004: 53). El ejemplo más similar a estas calderas, tanto por morfología como por dimensión, sería el de la de la oficina pompeyana $\mathrm{V}, 1,5$, de la que se ha efectuado incluso una estimación de su cubicaje -unos 270 l- (Borgard y Puybaret, 2004: 54). Y en tercer lugar y para finalizar, la existencia de una zona diáfana donde poder llevar a cabo el secado de los tejidos (Puybaret, Borgard y Zérubia, 2008: 192), que en el caso emeritense quedaría incluido en la zona donde se localizan las piletas.

\subsection{La preservación de los tejidos}

La composición natural de los tejidos lleva consigo unos cuidados concretos y específicos que 

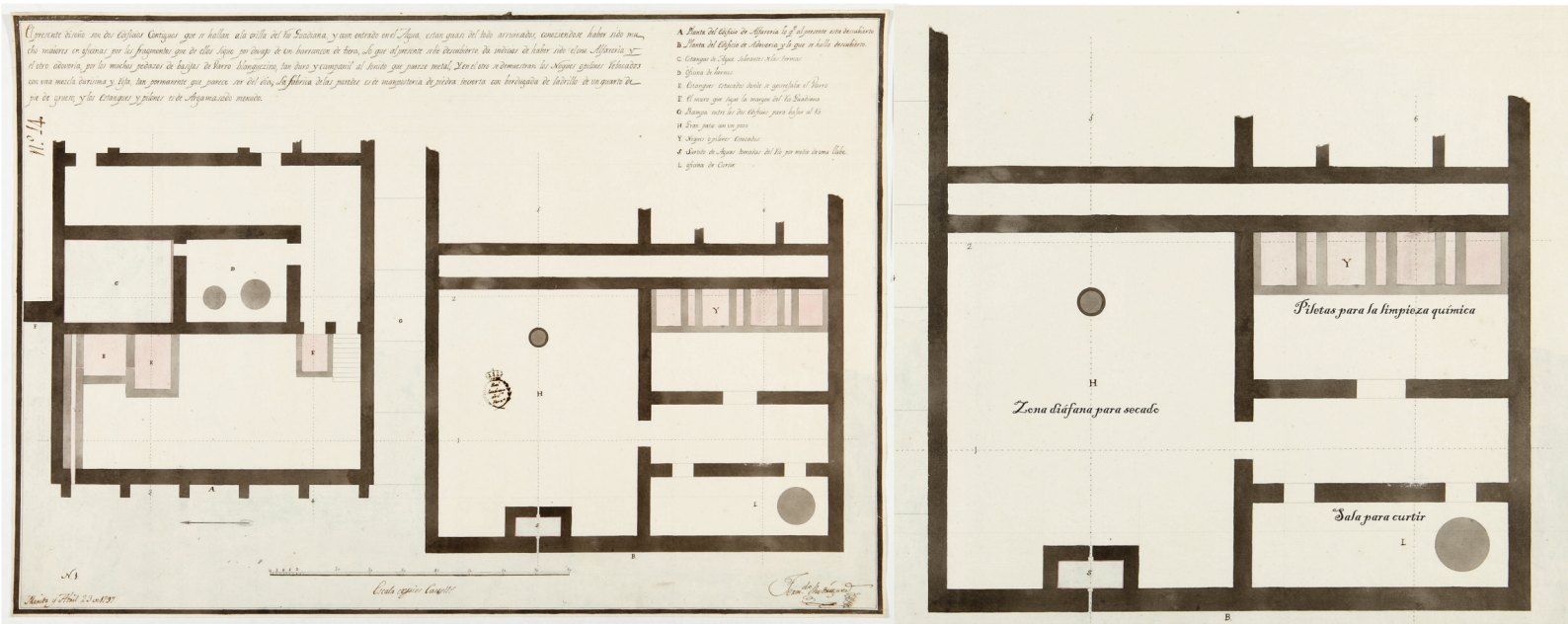

Fig. 10. Planta de Fernando Rodríguez y la posible reinterpretación de la fullonica (imagen cortesía: C. Morán y A. Pizzo).

no se podían desarrollar en ámbito doméstico. Estos procesos de preservación eran en sí mismos actividades consideradas como de lujo y apoyo para el mantenimiento y no para el uso cotidiano de las prendas (Flohr, 2011).

\subsubsection{Las fullonicae ${ }^{8}$}

El trabajo desarrollado en las fullonicae es una rama más del tratamiento de los textiles en época romana. Su objetivo fundamental era mejorar las calidades de las prendas, recobrando su aspecto original o haciendo de ellas más confortables al uso, por lo que no pueden considerarse dentro del proceso de producción de textiles. Por lo tanto, en sí misma esta actividad no es necesaria para el uso de las prendas, sino más bien responde a pautas sociales impuestas ya en época romana, de ahí que se haya considerado más un servicio de lujo que una actividad manufacturera (Flohr, 2011: 229).

Las fullonicae se caracterizan por presentar una serie de hitos que nos permiten definir una instalación como tal. Así el proceso químico por el

${ }^{8}$ Expresamos nuestra gratitud a los arqueólogos T. Barrientos, F. Palma y P. D. Sánchez por los datos e ideas aportadas para el desarrollo de este trabajo. cual los textiles deben pasar hace que las piletas sean elementos indispensables, con una morfología precisa (Flohr, 2005: 59-60). Para Pompeya, se localizan ejemplos de pequeñas dimensiones a modo de nichos reducidos -entre 2 y 4 - instalados en batería, delimitados con muros de pequeña altura, recubiertos de opus signinum y con salida al exterior por medio de canales (caso de la VI, 14, 21-22; la I, 4, 7, o la VII, 2, 41). Asimismo, se hace muy común la aparición de muretes enfrentados a las piletas para dejar los productos una vez tratados y canales inferiores que permitan recoger el líquido escurrido de las prendas -caso de la fullonicae V, 1, 2-.

La primera de las instalaciones que asociamos directamente a una fullonica es el segundo edificio recogido por F. Rodríguez a fines del s. XVIII y ubicado al sur de lo que hemos interpretado como officina infectoria, a los pies del Guadiana (Fig. 10). Nos encontramos ante un edificio de planta cuadrangular que fue interpretado por el autor como "adoveria, sala de curtir", entendiéndose como el espacio que denominamos en la actualidad "tenerías", es decir, zonas destinadas al procesado de pieles. De primera desechamos dicha hipótesis puesto que las tenerías tienen una serie de características comunes -como las piletas circulares- que en este caso no se reproducen - para más datos ver las intervenciones realizadas en la conceria de Pompeya-. Sin embargo, este 
autor no se alejó mucho de lo que creemos que fue la actividad desarrollada. A nuestro modo de ver, estamos ante una fullonica. Las claves al respecto las aporta la estancia Y. En ella se localizan cuatro nichos rectangulares, ubicados en batería y sin conexión entre ellos -hecho que diverge del edificio colindante-. De hecho, la separación se remarca a partir de unos muros de menor grosor, ejemplos de estos elementos son habituales en Pompeya. El caso más clarificador lo localizamos en una pintura donde aparecen cuatro fullones trabajando y enmarcados en cuatro nichos separados por muretes que permiten al individuo apoyarse y trabajar en mejores condiciones (casa VI, 8, 2.20-21).

Según se recoge en el dibujo de F. Rodríguez existirían tres estancias más: una de tránsito, la estancia denominada L, que define como oficina de curtir, y un espacio diáfano con pozo y fuente. La estancia L por el elemento circular establecido creemos que haría referencia a un espacio para el calentado de algún material necesario para las actividades desarrolladas. Echaríamos en falta piletas asociadas al lavado final de los tejidos, sin descartar que se localizaran en otras zonas no excavadas del complejo, aunque se dan casos en los que no se presentan, como la fullonica de Primus en la Vía Stabia (VI, 14), cuyo esquema es muy similar al presentado.

Por consiguiente, si tenemos en cuenta la cercanía entre ambas instalaciones entendemos una organización gremial del espacio, al menos, en la orilla norte del río Guadiana.

La siguiente instalación analizada (Fig. 11) es la localizada en 1999 durante una intervención de urgencia en el solar de la c/ Calvario, 59 (Palma, 2001a). En esta excavación se documentó un espacio industrial de unos $30 \mathrm{~m}$ de largo y anchura de, al menos, unos $10 \mathrm{~m}$. Aunque en muy mal estado de conservación se localizaron, al menos, cinco piletas posicionadas en batería y de dimensiones variables $(3 \times 1,5 \mathrm{~m}$ o $3 \times 1 \mathrm{~m})$. El estado de conservación no nos permite apreciar si estarían o no interconectadas, pero entendemos que la proximidad entre ellas daría pie a ello. En la zona suroeste al solar, y enfrentado a dos de las piletas, se localizaría un pretil con un pequeño canal en la zona inferior. Ejemplos similares han sido hallados en Pompeya -fullonica V, 1, 2- y sería un canal destinado a recoger el líquido que escurriría de la prenda apoyada en dicha baranda. Al igual que las otras instalaciones que venimos abordando, la cercanía al curso del Guadiana, por un lado, y al castellum aquae, por el otro, serían claves para su desarrollo.

Otra fullonica fue localizada en la c/ Forner y Segarra ${ }^{9}$. Además hay constancia de otras posibles instalaciones inéditas que han sido asociadas a este tipo de complejos, como una en la Alcazaba, en la c/ Marquesa de Pinares o en el área de servicio del anfiteatro (Alba, 2012: 355-356), que deberán ser valoradas en un futuro.

A excepción de las instalaciones localizadas en el entorno del río podemos decir que, aunque no existe un patrón de ubicación, se reitera la aparición intramuros. Frente a lo que podríamos sobrentender que generasen una polución extrema, no debió ser así si observamos la constante ubicación en el interior de las murallas de la ciudad, no sólo en este caso, sino en otros estudiados; así por ejemplo en Pompeya se observa una fuerte concentración en el entorno del vicolo del Balcone pensile o de algunos templos (Borgard y Puybaret, 2004: 49-50, fig. 2). $\mathrm{Su}$ cercanía a los ambientes forenses hizo que algunos investigadores no interpretaran con exactitud la función de las estructuras localizadas (Alvarado, Molano y Gijón, 1991: 1008).

Vinculados indirectamente con la producción o con la conservación de los textiles estarían los recipientes encargados de la recuperación de orines para el blanqueado en las fullonicae. Recordar que la orina era parte fundamental para el proceso de blanqueado de los textiles. Era tal la industria generada de la recogida de este producto que durante el reinado de Vespasiano, como nos cuenta Suetonio, se impuso una tasa sobre la recogida de estos productos. Para el caso emeritense durante la intervención de la avda. de Lusitania se identificó un urinario portátil para la recogida del líquido tan preciado para esta industria (Méndez y Alba, 2005: lám. 12).

\section{La producción de cal}

La cal se obtiene por la termoalteración a altas temperaturas de la piedra caliza. Este material fue necesario para la construcción en época romana siendo muy frecuente su uso en los paramentos

\footnotetext{
${ }^{9}$ Intervención inédita realizada por J. L. Mosquera y J. Márquez, citada por Alba (2012: 355-356).
} 

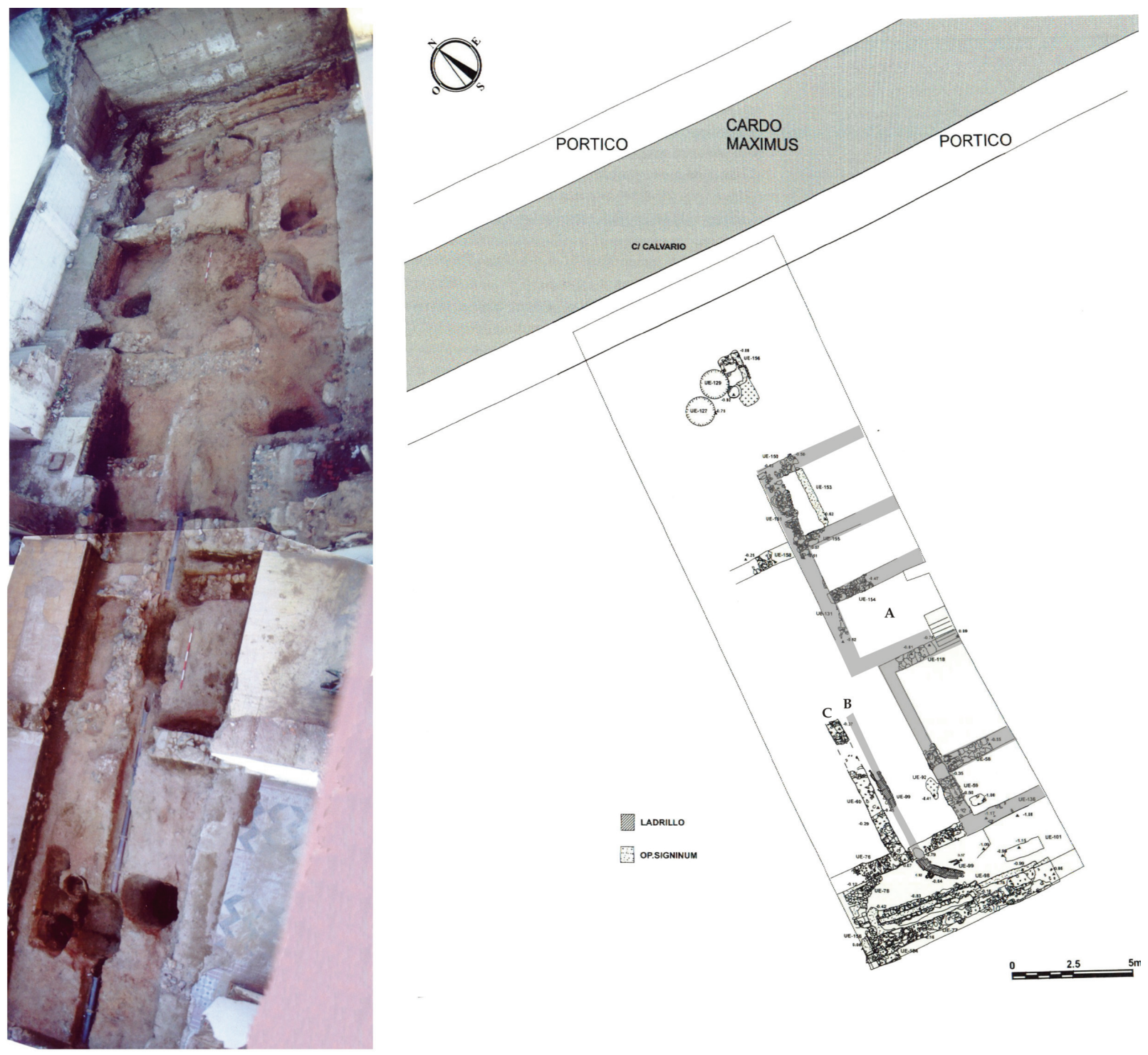

FIG. 11. Fullonica de la cl Calvario. Imagen del solar y reconstrucción de la planta: A. Piletas; B. Canal de desagüe y $C$. Poyete para el secado de las prendas (montajes a partir de F. Palma, 2001a: láms. 1 y 2).

emeritenses - para profundizar $c f$. Pizzo, 2010-. El proceso por el cual la piedra caliza se convierte en cal es lento y laborioso necesitándose una estructura donde se produzcan estos cambios que ahora valoraremos - para detalles sobre todo el proceso $c f$. Adam, 2005: 69-. Primero se debe calentar a altas temperaturas, generando la denominada cal viva, que se presenta a modo de pequeños coágulos que, inmersos en agua, desprenden calor y se convierten en cal muerta presta a ser mezclada y utilizada como aglutinante. El procedimiento es ampliamente conocido no solo por hallazgos arqueológicos, sino también por las distintas referencias que nos han legado los autores clásicos como Catón el Viejo -en el capítulo "De fornace calcaria" dentro de su Tratado de Agricultura- o Vitrubio -De Architectura II, V, 109-.

Para Mérida podemos distinguir, a día de hoy, cuatro complejos vinculados a la generación de cal; todos se ubican en zonas muy alejadas del 
núcleo poblacional, a diferencia de lo que venimos viendo para las otras actividades. Se observa una concentración en el entorno de la Sierra $\mathrm{Ca}$ rija, gracias a la fuerte presencia de vetas calizas (Alba, 2012: 353). La proliferación de las estructuras vinculadas a la producción de cal ha tenido una fuerte continuidad en el tiempo hasta la época moderna como demuestran algunos estudios etnográficos (ibidem: 353-354).

El complejo mejor conocido se localiza en una villa ubicada en el entorno de la Vía de la Plata (Nodar y Grajera, 2004). En él se hallaron dos hornos cerámicos de planta cuadrangular y un horno con planta en omega que fue determinado como calera. Dicho horno poseía un diámetro de 3,76 m, un alzado troncocónico y una factura de ladrillos trabados y muy rubefactados. Destacamos cómo la entrada a la cámara se encontraba flanqueada por dos bloques pétreos, hecho que también se ha documentado en los otros ejemplares localizados y que posiblemente esté relacionado con el mantenimiento de la temperatura.

El segundo horno fue localizado en uno de los solares de La Heredad, asociado directamente a un complejo alfarero ${ }^{10}$. En este solar, además de un horno de planta circular -con diámetro de 2,30 $\mathrm{m}-$, se localizaron una serie de fosas excavadas directamente en la roca - de $2 / 3 \mathrm{~m}-$ y con una tonalidad blanquecina. Estas fosas estarían vinculadas al proceso del apagado de la cal viva.

El tercero de los complejos se ha localizado en el entorno de Las Abadías ${ }^{11}$; en esta misma zona, durante las actuaciones destinadas al proceso de ensanche de la carretera de Proserpina (Alba, 2012: 354), se identificaron otros hornos de cal.

En momentos posteriores, su uso se extenderá por toda la ciudad teniendo siempre la filosofía del reciclado de los productos marmóreos romanos; un ejemplo de lo indicado lo encontramos en el solar de Morerías (Alba, 1999: lám. 12).

\section{Otras actividades artesanales}

Existen otras actividades que evidentemente se desarrollaron en Mérida para las que su huella palpable únicamente son los elementos resultantes.

${ }^{10}$ Agradecemos los datos inéditos aportados a J. Ortega.

${ }^{11}$ Solar intervenido por G. Méndez recientemente.
La orfebrería estuvo bien arraigada como podemos deducir al analizar el amplio elenco de joyas aparecidas en la región que comparten rasgos compositivos similares. Además, en el solar emeritense se ha localizado una inscripción donde aparece el nombre de un margaritarius (orfebre), Silvanus (CIL II, 496), lo que de nuevo nos habla de un artesanado urbano (Casal, 1999: 378). En un entorno relativamente cercano a la ciudad, concretamente en la pacense Villa de la Cocosa, apareció una cacerola monoansada con el sigillum EX OF ASEELUS y un crismón asociado, interpretado como Asellius (Serrá Rafols, 1952: 153, lám. 28; García y Bellido, 1955: 19). La relativa proximidad de esta villa a la capital lusitana y la constatación en Mérida de este nomen apuntan a un posible taller local regentado por este artesano (VV. AA., 2003: 102).

También la glíptica tendría un campo de actividad en la ciudad, aunque aún no es posible precisar si hubo un taller local (Luzón, 1982; Olmedo, 2009: 445-449).

Respecto a la producción toréutica se puede apuntar la existencia de un arnés de cronología visigoda firmado por Neglectus (García y Bellido, 1955: 19). Para el trabajo del metal, existen referencias al trabajo del estańo en el entorno emeritense; en este sentido apunta la lectura de un epígrafe sobre un lingote de estaño procedente del pecio de Port-Vendrès (Colls et al., 1975; 1977: 18-22) en el que se puede leer L(ucius) Vale(rius) Aug(ustae) l(ibertus) a com(mentariis) (Mangas y Orejas, 1999: 273-274).

En Mérida se han localizado restos de algunos talleres de fundición. El primero de ellos, de cronología tardía, en la c/ Calvario, 8 (Ayerbe, 2005); es una instalación muy sencilla, a partir de subestructuras circulares necesarias para los procesos de combustión. El segundo está en la c/ Adriano, 5 (Ayerbe, 2007), datado en el s. V d. C., con una ordenación espacial muy concreta y dentro de los límites públicos, que supone una reorganización del espacio municipal emeritense. Ambas estructuras se caracterizan por estar asociadas a crisoles y restos abundantes de escoria.

Dentro del mundo de la metalurgia cabría también la posibilidad de que existiera un taller de escultura broncínea que produciría, a tenor de los especialistas, piezas de alta calidad en los primeros 
siglos imperiales (Nogales, 1990: 103; Ayerbe, 1999: 345). Para momentos posteriores conocemos un amplio desarrollo de las labores de fundición; un ejemplo lo encontramos en el solar de Morerías (Alba, 1999: 406-407), donde se ha advertido un proceso de reciclado claro de piezas romanas altoimperiales.

Una de las industrias metalúrgicas más desarrolladas fue la del trabajo del plomo. En este caso las fistulae aquariae localizadas en territorio emeritense dan muestra de ello. Hoy en día conocemos seis nombres asociados a plumbarii, los cuales de manera directa firmaban estos productos. Dichas marcas son las siguientes: EX OF(ficina) FELICISIS, EX. $O F($ ficina). $M($ arci) I(-) $A(-), E X O F($ ficina). $G$ (aii) $I(-) P(-), E X . O F($ ficina).L(ucii).MO., L(ucius) SA(?) RVF(ini) y (offic)INA VENERIAN(i) -lecturas de Saquete (2001)-. El hecho de que aparezcan abreviados sus tria nomina nos indica que puede tratarse bien de libres o de libertos; sin embargo, no podemos pensar en personas con un alto nivel social al tratarse de un negocio poco rentable y expuesto a graves problemas de salud (Saquete, 2001: 154). Estas marcas se complementan con otras de carácter municipal -caso de CIAE-, hecho que no nos debe de extrañar pues estamos hablando de piezas necesarias para el saneamiento público. Los nombres individualizados de los plumbarii sugieren dos opciones: en primer lugar, que el tejido productivo municipal no pudo hacer frente a toda la demanda de la ciudad y en segundo lugar, que se pudo tratar de una locatio conductio entre el ente municipal y talleres individuales como ya se ha documentado en Roma (Bruun, 1991: 305).

El vidrio también debió ser una de las actividades bien establecidas y prósperas en suelo emeritense. Al igual que sucede con otras actividades ya comentadas, resulta muy difícil rastrear sus medios de producción. La abundante aparición de recipientes vítreos ya hizo plantearse desde antiguo la producción local en la capital de Lusitania -entre otros, Macías (1934-35: 383)-. Hoy es posible establecer hasta cinco zonas donde se podría haber producido este material. En primer lugar, en la c/ Reyes Huertas (Caldera, 1980: 139), donde se localizaron una serie de estancias con morfología muy similar a los talleres vidrieros. En segundo lugar, en la zona conocida como Molino de Pancaliente (ibidem), donde se han recuperado pellas de material vítreo puro presto a ser modelado así como moldes. En tercer lugar, en la c/ J. R. Mélida (Caldera, 1980: 140), donde se repiten los elementos hallados -materia prima, moldes y estructuras similares-. En cuarto lugar, en el entorno del Cerro de San Albín, donde de nuevo se advierten restos claramente asociados a la manufactura del vidrio (Caldera, 1980: 140-141). Recientemente podemos añadir a este listado un ejemplo más, localizado en la $\mathrm{cl}$ Almendralejo, 41, donde además de las estructuras típicas apareció un horno circular de escasas dimensiones asociado a restos de materia prima que no hicieron dudar de su funcionalidad ${ }^{12}$.

Otros elementos disponibles sobre la actividad vidriera son las marcas de producción localizadas en Mérida y para las que se ha supuesto un origen local; hay sellos fitomórficos (Pryce, 2006: pl. 1, n. ${ }^{\text {os }}$ 008-009), zoomórficos (Pryce, 2006: pl. 4, n. os $^{\circ}$ 037 y 047$)$ o nominales. Entre estos últimos son de destacar las selladas por CBL, LL.F (Pryce, 2006: pl. 6, n. ${ }^{\circ} 064$ y pl. 7, n. $\left.{ }^{\circ} 074\right)$ cuya distribución únicamente se focaliza en Mérida y cuyas analíticas han permitido determinar que su naturaleza estaba emparentada con la diorita de la cuenca del Guadiana (Caldera, 1982: 141) ${ }^{13}$.

La eboraria es otra labor rastreable en Mérida (Fig. 12). Se localiza una actividad muy fructífera constatada por el amplio elenco de piezas localizadas y la reiteración de otras que claramente nos hablan de un foco productor en la zona. Además de esta koiné decorativa que induce a pensar en una producción local/regional, encontramos elementos del proceso productivo de esta actividad, como son los desbastes y pasos previos para el tallado final de esta materia prima. Un ejemplo de ello se ha localizado en un vertedero ubicado en el suburbio norte con una ingente cantidad de restos vinculados a esta producción (Aranda, 2006). De igual modo, se encuentra en curso de estudio una concentración de desbastes localizada en la ocupación tardía del anfiteatro que nos

12 Agradecemos el dato aportado por A. B. Olmedo.

13 Cf. también Caldera, P.: Estudio sobre vidrios romanos emeritenses, memoria de licenciatura inédita presentada en 1980 en la Univ. de Sevilla. 

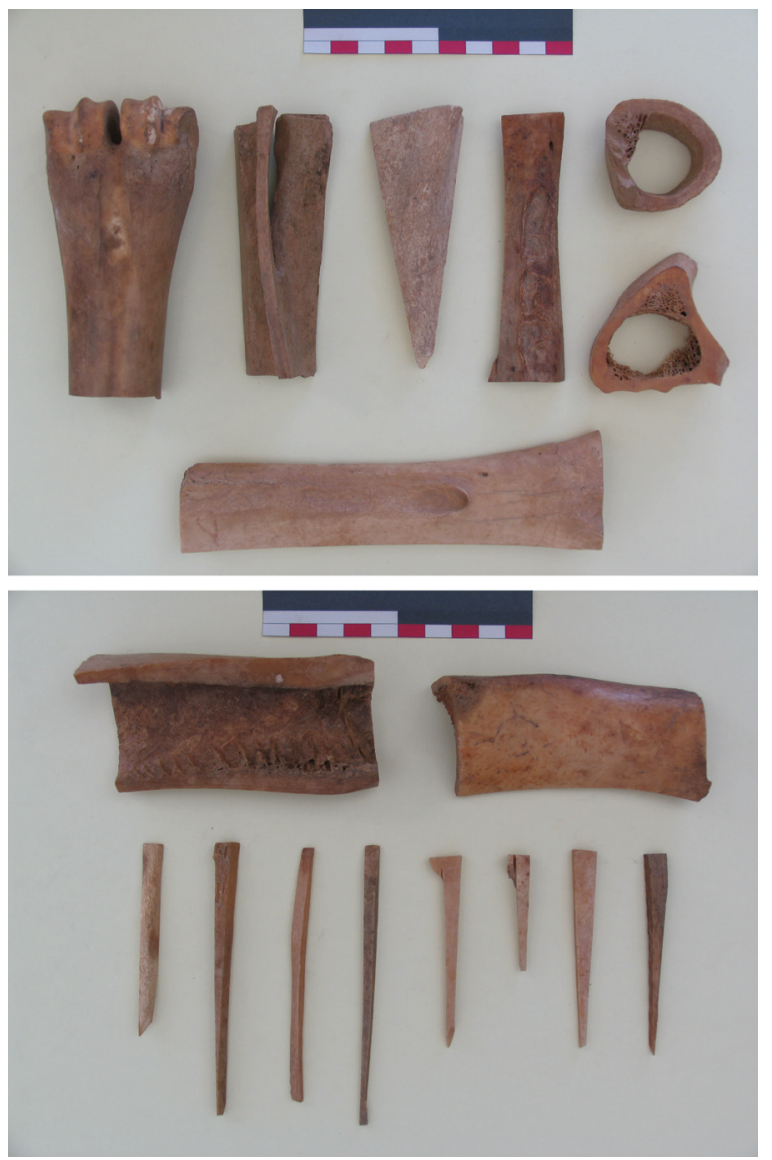

FIG. 12. Imagen del proceso del tallado del hueso procedente del vertedero de la cl Almendralejo, 41 (Aranda, 2006: fig. 6).

hablan de una reconversión funcional de los espacios a fines del periodo romano ${ }^{14}$.

Existen otras actividades bien estudiadas en Mérida y que tienen un ámbito espacial más allá del meramente urbano como son los trabajos lapicidas. Ejemplos de ello son la musivaria, con un gremio artesanal bien delimitado por un supuesto C(ollegium) A(rtificium) E(emeritensium) -CIL II, 492- personalizado en los artesanos Seleucus, Anthus -CIL II, 492-, Baritto (Lancha, 1994: 6),

\footnotetext{
${ }^{14}$ Este estudio se enmarca en el proyecto "Teatro y anfiteatro de Augusta Emerita: documentación, investigación y presentación de dos edificios de espectáculo de fecha romana" (Plan regional de Investigación de la Junta de Extremadura y Programa Euromed IV Heritage) dirigido por P. Mateos y A. Pizzo.
}

Partenos (Lancha, 1994: 125) o Annius Ponius (MosHispa-BA, 10, Lancha, 1994: 124). El trabajo del mármol también es bien conocido a través de las inscripciones de Gaius Aulus, Gauis Aulus Fidus, Caius Ateius Aulus (CIIAE 82; García y Bellido, 1955: 6-7; Cisneros, 1988: 46) o $\triangle \mathrm{HMHTPIO \Sigma}$ (García y Bellido, 1955: 7), interpretadas como jefes de oficinas y no como escultores propiamente (Cisneros, 1988: 53). Además de estas firmas para esculturas de bulto redondo encontramos nombres de marmolistas dedicados a la decoración arquitectónica, caso de РОПО HYLLU (García y Bellido, 1955: 8).

Para finalizar, otra de las actividades artesanales que también estuvo muy arraigada en Mérida fue la decoración pictórica parietal. Aunque no podemos asociar espacios a esta, sí se puede hacer referencia a un grupo organizado y con rasgos característicos propios (Barrientos y Guiral, 2007: 170-171). En este sentido, en la ciudad emeritense se ha definido una decoración pictórica asociada al relieve -recientemente también documentada en Cartagena- cuyo estudio nos permite hablar de un contingente productivo, a modo de taller local, muy restringido geográficamente a Mérida. De igual modo se ha localizado en la Casa del Anfiteatro la firma de un individuo en un lienzo con decoración parietal; se trata de Quintosus, nombre que parece corresponder a un esclavo (Abad, 1976: 176; Guiral y Mostalac, 1994: 154).

Existirían otras industrias no rastreables en sus contextos productivos, pero sí a través de sus productos finales, como el trabajo de la madera. Los casos más claros los identificamos iconográficamente en la musivaria, la cestería o el calzado -como el ejemplo localizado en la c/ Concejo (Barrientos, 2007: 382-383, fig. 18)-.

Finalmente queremos comentar otras actividades que, aunque tradicionales, no pueden ser consideradas como artesanales ya que no suponen la transformación de una materia prima. Uno de los ejemplos claros al respecto lo tenemos en la pesca: la de tipo fluvial está constatada en Mérida gracias a los abundantes anzuelos localizados en la ciudad. Otra realidad bien distinta serían todas las actividades subsidiarias generadas al amparo de ésta, como la confección de redes y la producción naval, ambos artesanados 
difícilmente rastreables en la actualidad. Sin embargo, en las excavaciones llevadas a cabo en el suburbio norte de la ciudad se han localizado enterramientos con piezas muy significativas que indican una vinculación directa del difunto con el mar, con tumbas en las que aparecen los aperos de estas gentes y conchas marinas.

\section{En búsqueda del artesanado emeritense}

Como hemos podido comprobar, para el estudio del artesanado emeritense es necesario acometer nuevas investigaciones que, con carácter interdisciplinar, permitan acercarnos a estas parcelas en toda su amplitud.
La ubicación de estas estructuras productivas que hemos ido analizando, en un amplio porcentaje, está a las afueras de la ciudad, pero en un entorno muy inmediato (Fig. 13), es decir, en su suburbium (Márquez, 2010: 150). En ningún momento se han localizado estructuras en el mismo corazón de la ciudad, lo que nos permite pensar en una organización espacial férreamente controlada.

Si analizamos espacialmente la ubicación de estos recintos vemos claramente una organización periférica articulada en 3 cinturones que envuelven su núcleo urbano:

- Un primer espacio dentro de la ciudad: en el estado actual del conocimiento únicamente podemos establecer dentro del perímetro urbano

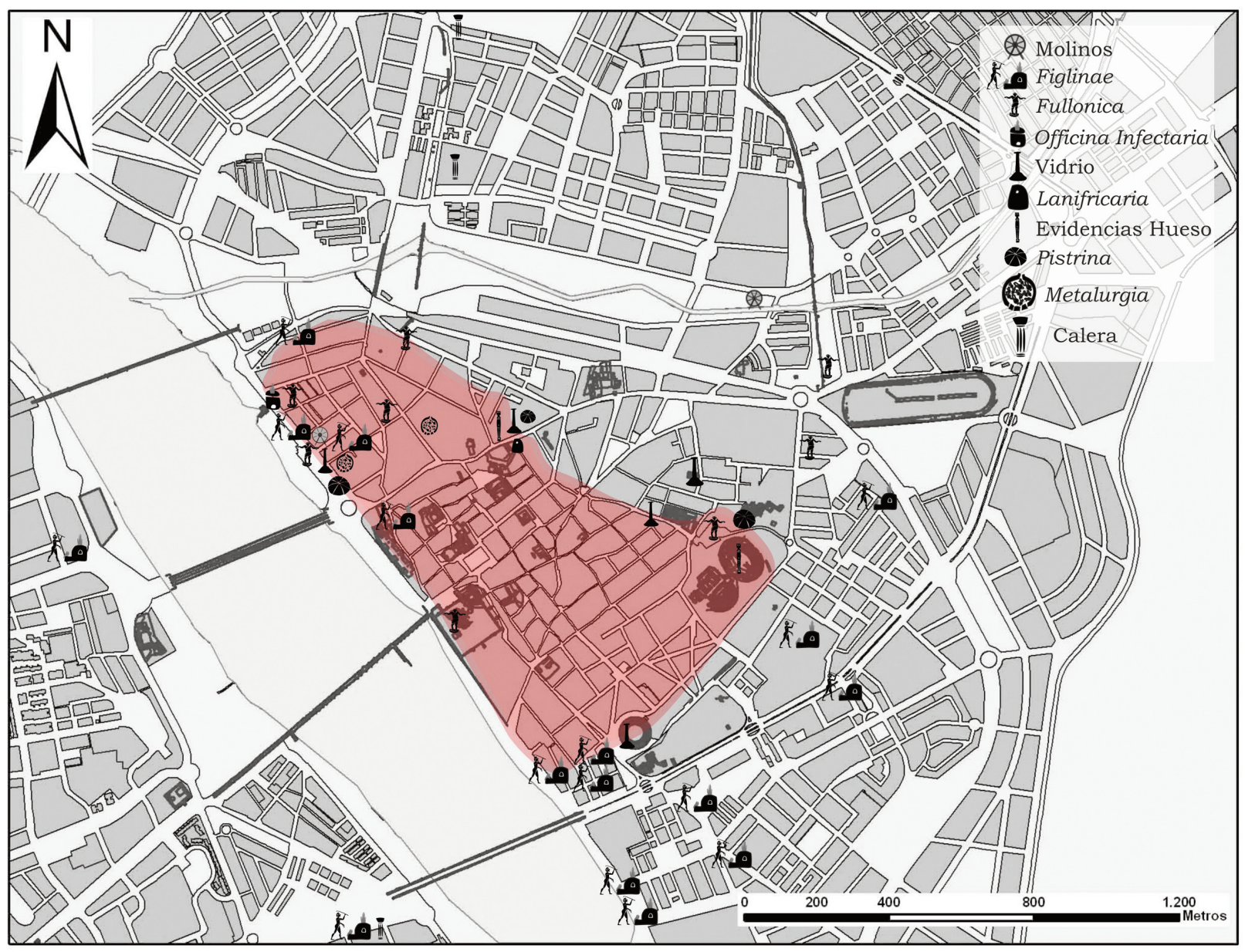

FIG. 13. Plano de Mérida con los talleres localizados. 


\begin{tabular}{|c|c|}
\hline Nombre & Labor profesional \\
\hline Silvanus & Orfebrería \\
\hline Asellius & Orfebrería \\
\hline Neglectus & Toréutica \\
\hline Lucius Valerius & Trabajo del estaño \\
\hline$C B L$ & Trabajo del vidrio \\
\hline$L L . F$ & Trabajo del vidrio \\
\hline Seleucus & Trabajo del mosaico \\
\hline Anthus & Trabajo del mosaico \\
\hline Baritto & Trabajo del mosaico \\
\hline Partenos & Trabajo del mosaico \\
\hline Annius Ponius & Trabajo del mosaico \\
\hline Gaius Aulus & Escultura \\
\hline Gaius Aulus Fidus & Escultura \\
\hline Caius Ateius Aulus & Escultura \\
\hline$\triangle H M H T P I O \Sigma$ & Decoración arquitectónica \\
\hline РОПОГ & Decoración arquitectónica \\
\hline М. ГАРГНА & Decoración arquitectónica \\
\hline Mais & Decoración arquitectónica \\
\hline HYLLU & Decoración arquitectónica \\
\hline Quintosus & Pintura \\
\hline$N S$ & Coroplastia \\
\hline PIL & Alfarería \\
\hline C.L. & Alfarería \\
\hline ETF & Alfarería \\
\hline INTIF & Alfarería \\
\hline GES & Alfarería \\
\hline Gabinia & Alfarería \\
\hline C.Oppi.Res & Alfarería \\
\hline Felix & Trabajo del plomo \\
\hline$M($ arcus $) I(---) A(---)$ & Trabajo del plomo \\
\hline$G($ aius $) I(---) P(---)$ & Trabajo del plomo \\
\hline$L$ (ucius) $M(---) O(---)$ & Trabajo del plomo \\
\hline Venerianus & Trabajo del plomo \\
\hline$L$ (ucius) Sa(.) R(ufus-inus & Trabajo del plomo \\
\hline
\end{tabular}

FIG. 14. Cuadro onomástico de artesanos emeritenses.

algunas fullonicae -como la de la estación de servicio del anfiteatro- o bien restos de talleres óseos -caso del localizado en el anfiteatro-.

- Un segundo espacio en el suburbium más inmediato. Ahí localizamos la mayor concentración de estructuras artesanales, siendo el caso ejemplificador la concentración en la orilla este del Guadiana. En esta zona, sobre todo, se acumulan las actividades vinculadas con la transformación y conservación de los textiles. Estas industrias, aunque generarían desperdicios, no serían un obstáculo para el desarrollo de las actividades cotidianas, como sí ocurrirá con las instalaciones del tercer cinturón.

- Un tercer complejo en las afueras de la ciudad agrupado, sobre todo, en el sur y el norte del municipio. En esta tercera franja se ubicarían las actividades que mayor polución generan. Entrarían ahí las que poseen procesos de combustión, caso de las alfarerías o la transformación de la cal.

Valorada la ubicación se observa una perfecta organización del espacio que en todo momento vela por un núcleo libre de aquellas actividades que entorpezcan el devenir normal del municipio. Hay que destacar cómo toda la ciudad se encuentra circunvalada por complejos artesanales, siendo la zona este la menos concurrida, hecho que achacamos a la propia dinámica de los vientos del lugar, que en esta zona arrastrarían directamente la polución hacia el centro urbano.

Socialmente podemos deducir una serie de rasgos básicos sobre el artesanado; en un alto porcentaje los nombres de artesanos localizados presentan un posible tria nomina abreviado. Predominan los libertos y los nombres de clara raíz oriental (Fig. 14).

Tampoco podemos precisar ningún dato sobre su organización laboral, a excepción de algunos casos de locatio conductio expresos entre el municipio y talleres individualizados. Pongamos como ejemplo las evidencias en los talleres alfareros -con las marcas C(olonia) I(ulia) A(ugusta) $E$ (merita) F(ecit) o E(merita) P(ecunia) P(ublica) (Sánchez y Alba, 1998a: 222) - o la labor de los plumbarii en las infraestructuras de saneamiento público. En ambos casos se plantea un intervencionismo privado en las obras publicas sin estar directamente vinculado con actos evergéticos, el caso claro lo tenemos en las marcas plúmbeas con alusiones directas a las officinae.

Analizando las marcas localizadas, hemos podido comprobar algunas fórmulas que expresan la vinculación entre el producto y su productor: ex officina, fecit o collegium. En primer lugar, el 


\begin{tabular}{|c|c|c|}
\hline $\begin{array}{c}\text { Ubicación/ } \\
\text { Ref. bibliográfica }\end{array}$ & Restos localizados & Interpretación \\
\hline C/ General Aranda, 42 (Bejarano, 1997) & Pavimentos opus signinum & Instalación doméstica altoimperial \\
\hline C/ Teniente Torres, 3 (Jiménez Ávila, 1997) & Pavimentos opus signinum & Instalación doméstica altoimperial \\
\hline C/ Adriano, 50 (Márquez, 1997b) & Balsas revestidas de opus signinum & Instalación doméstica altoimperial \\
\hline C/ Ruiz Picasso, 11 (Márquez, 1997b) & Pavimentos opus signinum & Instalación doméstica altoimperial \\
\hline $\begin{array}{l}\text { C/ Francisco Almaraz esquina con c/ Forner y } \\
\text { Segarra (Casillas, 1997) }\end{array}$ & Pavimentos opus signinum & Instalación doméstica altoimperial \\
\hline C/ Oviedo, 24 (Márquez, 1997d) & Pavimentos opus signinum & Instalación doméstica altoimperial \\
\hline C/ Adriano, 45 (Barrientos, 1999a) & Pavimentos opus signinum & Instalación doméstica altoimperial \\
\hline C/ Forner y Segarra, 27 (Palma, 1999) & Pavimentos opus signinum & Instalación doméstica-industrial altoimperial \\
\hline C/ Cárdenas, 5 (Sánchez Sánchez, 1999a) & Pavimentos opus signinum & Instalación doméstica romana \\
\hline $\begin{array}{l}\text { C/ Hernán Cortes, } 12 \\
\text { (Sánchez Sánchez, 1999b) }\end{array}$ & Pavimentos opus signinum & Instalación doméstica romana \\
\hline $\begin{array}{l}\text { C/ Pizarro, } 61 \\
\text { (Barrientos, 1999b) }\end{array}$ & Pavimentos opus signinum & Instalación doméstica romana \\
\hline $\begin{array}{l}\text { C/ Guardia Civil, } 10 \text { c./v. c/ Vía Ensanche, s/n } \\
\text { (Sánchez Sánchez, 1999c) }\end{array}$ & Pavimentos opus signinum & Instalación doméstica romana \\
\hline C/ Sagasta, 3 (Sánchez Barrero, 1999) & Pavimentos opus signinum & Instalación doméstica romana \\
\hline C/ Ventosillas, 11 (Barrientos, 1998) & Pavimentos opus signinum & Instalación doméstica romana \\
\hline C/ Cabo Verde (Ayerbe y Márquez, 1998) & Estructuras varias & Instalación doméstica industrial \\
\hline $\begin{array}{l}\text { Avda. Fernández López } \\
\text { (Sánchez Barrero, 2000) }\end{array}$ & Pavimentos opus signinum & Instalación industrial altoimperial \\
\hline C/ John Lenon, 28 (Palma, 2000) & Pavimentos opus signinum & Instalación doméstica altoimperial \\
\hline C/ Muza, 38 (Barrientos, 2001) & Balsa recubierta de opus signinum & Instalación industrial altoimperial \\
\hline Barriada de las Tres Casas (Sánchez, 2001) & Balsa recubierta de opus signinum & Instalación industrial altoimperial \\
\hline C/ Ramón y Cajal, 10 & Balsa recubierta de opus signinum & Instalación industrial altoimperial \\
\hline C/ Mateo Guillén, 6 (Estévez, 2002a) & Pavimentos opus signinum & Instalación doméstica alto- y bajoimperial \\
\hline $\begin{array}{l}\text { C/ Tomás Romero de Castilla, s/n } \\
\text { (Palma, 2002) }\end{array}$ & Balsas recubiertas de opus signinum & Instalación industrial altoimperial \\
\hline C/ Cánovas del Castillo, 20 (Estévez, 2002b) & Pavimentos opus signinum & Instalación doméstica alto- y bajoimperial \\
\hline C/ Constantino, 60 (Barrientos, 2004) & Pavimentos opus signinum & Instalación doméstica altoimperial \\
\hline $\begin{array}{l}\text { C/ J. R. Mélida-Pontezuelas-Travesía de } \\
\text { Rambla (Bejarano, 2005) }\end{array}$ & Pavimentos y piletas con opus signinum & Instalación doméstica altoimperial \\
\hline Asamblea de Extremadura (Palma, 2005) & Pavimentos de opus signinum & Instalación doméstica altoimperial \\
\hline Avda. Juan Carlos I (Sánchez Barrero, 2007b) & Pavimentos opus signinum & Instalación industrial \\
\hline C/ Vespasiano, 27 (Rodríguez y Feijoo, 2007) & Pavimentos opus signinum con cuarto de caña & Instalación doméstica altoimperial \\
\hline C/ Adriano, 5 (Ayerbe, 2007) & Pavimentos opus signinum & Instalación doméstica \\
\hline C/ Hernán Cortes, 37 (Bejarano, 2007) & $\begin{array}{l}\text { Pavimentos de opus signinum y acumulación } \\
\text { de material constructivo }\end{array}$ & Instalación doméstica altoimperial \\
\hline C/ Augusto, 4 (Barrientos, 2006) & Balsa revestida de opus signinum & Instalación industrial altoimperial \\
\hline $\begin{array}{l}\text { C/ Francisco Almaraz, } 30 \text { (Dpto. } \\
\text { Documentación del Consorcio, 2006a) }\end{array}$ & Balsa revestida de opus signinum & Instalación industrial bajoimperial \\
\hline C/ Cabo Verde, 9 (Olmedo, 2006) & Pavimentos opus signinum & Instalación industrial alto- y bajoimperial \\
\hline C/ Pontezuelas 44 (Ayerbe, 2006) & Pavimento opus signinum & Instalación industrial altoimperial \\
\hline $\begin{array}{l}\text { C/ Castellar, } 5 \\
\text { (Dpto. Documentación del Consorcio, 2006b ) }\end{array}$ & Pavimento opus signinum & Instalación doméstica altoimperial \\
\hline C/ Romero Leal, 11 (Palma, 2006) & Pavimento opus signinum & Instalación doméstica bajoimperial \\
\hline $\begin{array}{l}\text { C/ Castelar, } 1 \\
\text { (Dpto. Documentación del Consorcio, 2006c) }\end{array}$ & Balsa revestida de opus signinum & Instalación industrial bajoimperial \\
\hline $\begin{array}{l}\text { C/ Tomás Romero de Castilla y A. Hernández } \\
\text { Gil (Méndez, 2006) }\end{array}$ & Estructuras varias & Instalación industrial altoimperial \\
\hline $\begin{array}{l}\text { Cruce c/ Pizarro y c/ López de la Vega } \\
\text { (Sánchez Barrero, 2006) }\end{array}$ & Pavimento opus signinum & Instalación doméstica bajoimperial \\
\hline
\end{tabular}

FIG. 15. Lugares del solar emeritense con presencia de opus signinum, balsas y otros elementos industriales. 
término officina, que según el Thesaurus Linguae Latinae se refiere a locus ubi aliquid fit hoc est in quo operarii opera sua faciunt, es decir, el lugar donde un operario hace su obra (Estienne, 1741: III, 338). En segundo lugar está la referencia expresa al collegium de musivarios que además habla de una corporación profesional. En tercer lugar, el verbo expreso de la acción, facere, también es un buen ejemplo de lo indicado.

Haciendo balance, la actividad mejor conocida es la alfarera, no sólo por el elevado número de evidencias localizadas, sino también por la tradición como tema de estudio. Le siguen en número de estructuras conocidas el tratamiento de los textiles y muy cerca de esta última están las otras manufacturas documentadas.

Recordemos que el núcleo poblacional de Mérida es uno de los más activos en lo que se refiere a actividad arqueológica. De hecho, son muchos los indicios que en la actualidad poseemos de actividad artesanal y que no pueden ser adscritos debido a la mínima parte documentada (Fig. 15). Esperamos que en un futuro esta línea de investigación se amplíe a partir del elenco aquí presentado.

\section{Bibliografía}

ABAD, L. (1976): "La pintura romana en Mérida". En Actas del Simposio Internacional Conmemorativo del Bimilenario de Mérida. Madrid, pp. 163-182.

Acero, J. (2011): "Augusta Emerita". En Remolá, J. A. y ACERO, J.: La gestión de los residuos urbanos en Hispania. Madrid, pp. 157-180.

ADAM, J. P. (2005): La construction romaine. Paris.

AlbA, M. (1999): "Sobre el ámbito doméstico de época visigoda en Mérida", Mérida. Excavaciones Arqueológicas, 1997. Memoria 3, pp. 387-418.

- (2005): "Un área funeraria islámica emplazada sobre un barrero de época romana. Intervención arqueológica realizada en un solar situado en la confluencia de la c/ Dámaso Alonso y la Avda. Lusitania (Mérida)", Mérida. Excavaciones Arqueológicas, 2002. Memoria 8, pp. 343-375.

- (2012): "La industria artesana en Augusta Emerita". En Álvarez, J. M. y Mateos, P.: Actas del Congreso Internacional 1910-2010. El yacimiento emeritense. Mérida, 2010, pp. 345-363.

Alba, M.; Márquez, J. y Saquete, J. C. (1999): "Intervención en un solar sito en el Camino del Peral s/n", Mérida. Excavaciones Arqueológicas, 1994-95. Memoria 1, pp. 94-104.
Alba, M. y MéNDez, G. (2005): "Evidencias de industria paleolítica y de un alfar emeritense en Augusta Emerita. Intervención arqueológica realizada entre la prolongación de la cl Anas y el final de la Avda. Lusitania", Mérida. Excavaciones Arqueológicas, 2002. Memoria 8, pp. 375-411.

Alvarado, M. y Molano, J. (1991): "Aportaciones al conocimiento de las cerámicas comunes altoimperiales en Augusta Emerita: el vertedero de la cl Constantino”. En Aquilué, X. y RocA, M.: Ceràmica comuna romana d'època Alto-Imperial a la Peninsula Ibèrica. Estat de la questió. Ampurias, pp. 281-297.

Alvarado, M.; Molano, J. y Gijón, M. E. (1995): "Excavaciones de urgencia en la $\mathrm{cl}$ Almendralejo, n. ${ }^{\text {ss }}$ 58-60, Mérida". En XXI Congreso Nacional de Arqueología. Zaragoza, pp. 997-1010.

ARANDA, J. A. (2006): "Primeros avances en el estudio de la industria ósea de época romana y tardoantigua hallada en las excavaciones del solar de la c/ Almendralejo n. ${ }^{\circ} 41$ (Mérida)". En Memoria 9. Excavaciones arqueológicas 2003, pp. 573- 588.

Arbaíza, S. y Heras, C. (1998): "Fernando Rodríguez y su estudio arqueológico de las ruinas romanas de Mérida y sus alrededores (1794-1797)", Boletín de la Real Academia de San Fernando, n.o 87, pp. 309-366.

AYERBE, R. (1999): "Escultura romana en bronce hallada en Morería", Mérida. Excavaciones Arqueológicas, 1997. Memoria 3, pp. 339-346.

- (2005): "La llamada 'Basílica de Laborde': identificación, ubicación y cronología. Intervención arqueológica realizada en el solar de la c/ San Juan, 7 (Mérida)", Mérida. Excavaciones Arqueológicas, 2002. Memoria 8, pp. 89-121.

- (2006): "Excavación de un solar situado extramuros en la antigua Augusta Emerita, junto al edificio romano de la actual c/ Reyes Huertas". Intervención arqueológica realizada en la calle Pontezuelas n. 44 (Mérida)", Mérida. Excavaciones Arqueológicas, 2003. Memoria 9, pp. 125-151.

- (2007): "Evolución y transformación de un cardo minor y su margo desde época romana hasta nuestros días. Intervención arqueológica realizada en el solar n. 5 de la cl Adriano (Mérida)", Mérida. Excavaciones Arqueológicas, 2004. Memoria 10, pp. 185-209.

Ayerbe, R. y MÁrquez, J. (1998): "Intervención arqueológica en el solar de la c/ Cabo Verde. Espacio funerario del Sitio del Disco", Mérida. Excavaciones Arqueológicas, 1996. Memoria 2, pp. 27-40.

BARRIENTOS, T. (1998): "Intervención arqueológica en el solar de la c/ Adriano 64. El Cerro del Calvario", Mérida. Excavaciones Arqueológicas, 1996. Memoria 2, pp. 27-40. 
- (1999a): "Intervención arqueológica en el solar de la c/ Adriano 45. Nuevos hallazgos en el Cerro del Calvario", Mérida. Excavaciones Arqueológicas, 1997. Memoria 3, pp. 25-40.

- (1999b): "Intervención arqueológica en el solar de la c/ Pizarro 61", Mérida. Excavaciones Arqueológicas, 1997. Memoria 3, pp. 197-214.

- (2001): "Secuencia ocupacional en las proximidades de la muralla romana. Intervención arqueológica realizada en el solar n. ${ }^{\circ} 38$ de la c/ Muza”, Mérida. Excavaciones Arqueológicas, 1999. Memoria 5, pp. 85-120.

- (2004): "Excavación en la maqbara andalusí de la zona sur de Mérida. Intervención arqueológica realizada en el solar n. 60 de la c/ Constantino", Mérida. Excavaciones Arqueológicas, 2001. Memoria 7 , pp. 15-34.

- (2006): "Evolución del trazado viario romano extramuros junto a la puerta norte", Mérida. Excavaciones Arqueológicas, 2003. Memoria 9, pp. 37-61.

- (2007): "Una figlina emeritense extramuros del s. I d. C. y la ocupación funeraria del espacio en épocas bajoimperial y andalusí. Intervención arqueológica realizada en el solar n. ${ }^{\circ} 19$ de la c/ Concejo (Mérida)", Mérida. Excavaciones Arqueológicas, 2004. Memoria 10, pp. 371-409.

BARRIENTOS, T. y GUIRAL, C. (2007): "La decoración en relieve de Mérida: un taller del s. I d.C.". En Circulación de temas y sistemas decorativos en la pintura mural antigua. Actas del IX Congreso Internacional de la AIPM. Zaragoza, pp. 165-172.

BEJARANO, A. (1997): "Intervención en un solar de la c/ General Aranda, n. ${ }^{\circ}$ 42", Mérida. Excavaciones Arqueológicas, 1994-1995. Memoria 1, pp. 36-43.

- (2000): "Intervención arqueológica en la nave Azkar (Polígono industrial El Prado. Un horno de época altoimperial", Mérida. Excavaciones Arqueológicas, 1998. Memoria 4, pp. 25-38.

- (2005): "Evolución de un espacio periurbano en la zona norte de Augusta Emerita. Intervención arqueológica realizada en los solares n. ${ }^{\text {os }} 2,3,6,9$, 10 y 11 de las c/ J. R. Mélida - Pontezuelas-Travesía de Rambla", Mérida. Excavaciones Arqueológicas, 2002. Memoria 8, pp. 131-158.

- (2007): "Una domus extramuros en los límites de la ciudad: nuevos aspectos de la urbanística y el trazado de la muralla de Augusta Emerita en la zona oriental", Mérida. Excavaciones Arqueológicas, 2004. Memoria 10, pp. 233-257.

Borgard, P. y PUYbaret, M.-P. (2004): "Le travail de la laine au debut de l'empire: l'apport du modele pompeien. Quels artisans? Quels equipements? Quelles techniques?”. En Alfaro, C.; WILD, J. P. y
Costa, B. (eds.): Purpuraea Vestes II. Textiles y Tintes del Mediterráneo en época romana. Valencia, pp. 47-59.

BRUN, J. P. (ed.) (2009): Artisanats antiques d'Italie et de Gaule. Mélanges offerts a Maria Francesca Buonaiuto. Naples.

BRUUn, C. (1991): The water supply of ancient Rome. A study of Roman Imperial Administration. Helsinki.

Bustamante, M. y Gijón, M. E. (2011): "Un fragmento de molde para pasteles hallado en Augusta Emerita (Mérida, Badajoz)", Boletín SECAH-Ex Officina, 2, pp. 39-40.

Bustamante, M.; Gijón, M. E. y Olmedo, A. (2010): "A new terracotta mould in Augusta Emeri$t a$ ". En Nogales, T. y RodÁ, I.: Roma y los modelos de difusión. Mérida, pp. 1019-1024.

Bustamante, M. y Heras, F. J. (2013): "Producción anfórica en Augusta Emerita (Mérida, Badajoz) y los nuevos hallazgos del solar de la Escuela de Hostelería”. En Bernal, D.; Juan, L. C.; Bustamante, M.; DíAZ, J. J. y SÁEZ, A. M. (eds.): Hornos, talleres $y$ focos de producción alfarera en Hispania (I Cong. Int. Ex Officina hispana, Cádiz, 2011). Monografías de la SECAH, I. Cádiz, pp. 239-253.

Caballero, J. (2004): Alejandro de Laborde y Mérida. Pequeñas historias de grandes grabados. Mérida.

Caldera, P. (1982): "Aspectos del vidrio romano de Mérida". En Homenaje a Sáenz de Buruaga. Madrid, pp. 137-145.

CANTO, A. (2001): La arqueología española en la época de Carlos IV y Godoy. Los dibujos de Mérida de Don Manuel de Villena Moziño 1791-1794. Madrid.

Casal, R. (1999): "La joyería". En Álvarez, J. M. y Almagro, M. (eds.): En el año de Trajano. Hispania. El legado de Roma. Madrid, pp. 376-383.

Casillas, I. (1997): "Intervención en el Polígono industrial El Prado", Mérida. Excavaciones Arqueológicas, 1994-1995. Memoria 1, pp. 104-115.

CerChiai, C. (2004): Cibi e banchetti nell'antica Roma.

Cisneros, M. (1988): Mármoles hispanos: su empleo en la España romana. Zaragoza.

Colls, D.; Étienne, R.; Lequement, R.; Lion, B. y MAYeT, F. (1977): L'épave de Port Vendrès et le commerce de la Bétique a l'époque de Claude. Archaeonautica, I. Paris: CNRS.

Colls, D.; Laubenheimer, F. y Lion, B. (1975): "Les lingots d'étain de l'épave Port-Vendrès II", Gallia, 33, pp. 61-94. http://dx.doi.org/10.3406/galia.1975.1514

Cullin-Mingaud, M. (2010): La vannerie dans l'Antiquité, Collection du Centre Jean-Berard. Naples.

EstéveZ, J. A. (1998): "Aplicación de la metodología arqueométrica al estudio de cerámicas: teoría y 
desarrollo práctico. El caso de un grupo de cerámicas localizadas en Mérida", Mérida. Excavaciones Arqueológicas, 1998. Memoria 4, pp. 583-609.

- (2001): "Nuevos datos para el conocimiento arqueológico de un gran espacio extramuros próximo al río Guadiana", Mérida. Excavaciones Arqueológicas, 1999, Memoria 5, pp. 141-163.

- (2002a): "La funcionalidad doméstica de un espacio intramuros a lo largo de la historia. Intervención arqueológica realizada en el solar n. ${ }^{\circ} 6$ de la cl Mateo Guillén", Excavaciones Arqueológicas en Mérida 2000, Memoria 6, pp. 17-24.

- (2002b): "Ocupaciones y vacíos poblacionales al interior del recinto intramuros. Intervención arqueológica realizada en el solar n. ${ }^{\circ} 20$ de la cl Cánovas del Castillo", Excavaciones Arqueológicas en Mérida 2000, Memoria 6, pp. 185-193.

Estienne, R. (1741): Thesaurus Linguae Latinae. Bâle.

Excoffon, P. y Lemoine, Y. (2008): "Les moules bivalves en terre cuité em Gaule romaine (territoire français): état dês lieux", Archéologies de Provence et d'ailleurs, Suppl. 5, pp. 567-580.

Flohr, M. (2005): "Ars Fullonia. Interpreting and contextualizing Roman Fulling”. En BRIAULT, C.; Green, J.; Kaldellis, A. y Stellatou, A. (eds.): Soma 2003. Proceedings of the 7th Annual Symposium on Mediterranean Archaeology. BAR Intern. Ser., 1391. Oxford: Archaeopress, pp. 59-63.

- (2011): "Exploring the limits of skilled craftsmanship. The fullonicae of Roman Italy". En MONTEIX, N. y TRAN, N.: Les savoirs professionnels des gens de métiers. Études sur le monde du travail dans les sociétés urbaines de l'empire romain. Naples, pp. 87-100.

GarCía y Bellido, A. (1955): "Nombres de artistas en la España romana", Archivo Español de Arqueología, XXVIII, pp. 13-19.

Gijón, M. E. y Bustamante, M. (2010): "Los sellos romanos de panadero: una aproximación a su estudio a partir de los depositados en el Museo Nacional de Arte Romano (Mérida)", Huelva en su Historia, 13, pp. 15-30.

Guiral, C. y MOSTALAC, A. (1994): "Pictores et albarii en el mundo romano". En Artistas y artesanos en la Antigüedad Clásica. Cuadernos Emeritenses, 8. Mérida, pp. 137-159.

JiMÉNEZ ÁvilA, J. (1997): "Intervención en un solar de la c/ Teniente Torres, n. ${ }^{\circ}$ 3", Mérida. Excavaciones Arqueológicas, 1994-1995. Memoria 1, pp. 54-68.

JuAN TOVAR, L. C. (1990): "Alfares y vías de comunicación en Hispania romana. Acercamiento a una relación". En La Red Viaria en la Hispania Romana. Tarazona-Zaragoza, pp. 293-300.

LANCHA, J. (1994): "Les mosaistes dans la partie occidentale de l'Empire romain". En Artistas y Artesanos en la Antigüedad Clásica. Cuadernos Emeritenses, 8. Mérida, pp. 119-136.

LEDUC, M. (2008): "Les pistrina volubilitains, témoins majeurs du dynamisme économique municipal", África Romana, XVII, pp. 475-505.

LUZÓN, J. M. (1982): "Los entalles romanos del Museo de Mérida". En Homenaje a Sáenz de Buruaga. Madrid, pp. 127-137.

MACíAs, M. (1934-35): Vidrios romanos del Museo emeritense. Mérida.

Mangas, J. y Orejas, A. (1999): "El trabajo en las minas en la Hispania Romana”. En Rodríguez NeILA, J. F.; GONZÁlez Román, C.; MANGAS, J. y Orejas, A.: El trabajo en la Hispania romana. Madrid.

MÁrQueZ, J. (1997a): "Intervención en el interior del estadio de futbol”, Mérida. Excavaciones Arqueológicas, 1994-95. Memoria 1, pp. 80-94.

- (1997b): "Intervención en un solar de la cl Adriano, n. ${ }^{\circ}$ 49", Mérida. Excavaciones Arqueológicas, 1994-1995. Memoria 1, pp. 116-121.

- (1997c): "Intervención en un solar de la c/ Ruiz Picasso, n. ${ }^{\circ}$ 11", Mérida. Excavaciones Arqueológicas, 1994-1995. Memoria 1, pp. 122-128.

- (1997d): "Intervención en un solar de la c/ Oviedo, n. 24", Mérida. Excavaciones Arqueológicas, 19941995. Memoria 1, pp. 168-177.

- (2010): "Los suburbios de Augusta Emerita en perspectiva diacrónica". En VAQUerizo, D. (ed.): Las áreas suburbanas en la ciudad histórica. Topografia, uso y función. Anales de Arqueología Cordobesa, 18, pp. 135-152.

MédArD, F.; Borgard, P. y Moulhérat, C. (2011): "Le travail du textile a Pompéi. Ateliers et restes de tissus”. En Alfaro, C.; Brun, J. P.; Borgard, Ph. y Pierobon, R. (eds.): Purpurae Vestae III. Textiles y tintes en la ciudad antigua. Nápoles-Valencia, pp. 83-90.

Médard, F.; Borgard, P. y Zérubia, R. (2008): "Teindre comme à Pompéi: approche expérimentale". En Alfaro, C. y Karali, L. (eds.): Purpureae Vestae II. Vestidos, textiles y tintes. Estudios sobre la producción de bienes de consumo en la antigüedad. Valencia, pp. 185-195.

MÉLIDA, J. R. (1925): Catálogo monumental de España: provincia de Badajoz. Madrid.

MÉLIDA, J. R. y MACÍAS, M. (1929): Excavaciones en Mérida. El Circo, los columbarios, las termas, esculturas y hallazgos diversos. Memoria de los trabajos practicados en 1926 y 1927. Memorias JSEA, n. 98. Madrid.

MÉNDEZ, G. (2006): "Desarrollo de un espacio agropecuario y funerario en la zona sur de la ciudad. 
Intervención arqueológica realizada entre las c/ Tomás Romero de Castilla y Antonio Hernández Gil (Mérida)", Mérida. Excavaciones Arqueológicas, 2001. Memoria 7, pp. 209-228.

Méndez, G. y Alba, M. (2004): “Un conjunto de hornos cerámicos romanos junto al río Anas. Intervención arqueológica realizada en un solar de la Avda. Lusitana, esquina con la c/ Dámaso Alonso (1 fase)", Mérida. Excavaciones Arqueológicas, 2001. Memoria 7, pp. 307-332.

Moeller, W. O. (1976): The wool trade in the ancient Pompei. Netherlands.

Monteix, N.; Sanna, A.; Coutelas, A.; Garnier, L.; Matterne, V. y Zanella, S. (2011): "Pompéi, recherches sur les boulangeries de l'Italia romaine", Antiquité, 123, pp. 306-313.

MONTEIX, N. y TRAN, N. (2011): Les savoirs professionnels des gens de métiers. Études sur le monde du travail dans les sociétés urbaines de l'empire romain. Naples.

Nodar, R. y Olmedo, A. B. (2004): "Una instalación industrial junto a la Vía de la Plata", Mérida. Excavaciones Arqueológicas, 2001. Memoria 7, pp. 209228.

Nogales, T. (1990): "Bronces romanos en Augusta Emerita”. En Los bronces romanos en España. Madrid, pp. 103-115.

Olmedo, A. B. (2006): "Nuevos ramales de la cocción moderna de San Lázaro. Intervención arqueológica realizada en el solar n. ${ }^{\circ} 51$ de la Avenida de Extremadura (Mérida)", Mérida. Excavaciones Arqueológicas, 2003. Memoria 9, pp. 37-61.

- (2009): "Tratamiento y estudio de piezas singulares de época romana (anillos y gemas)". En AYerbe, R.; BARRientos, T. y PAlma, F.: El foro de Augusta Emerita. Génesis y evolución de sus recintos monumentales. Mérida, pp. 445-449.

Palma, F. (1999): "Intervención arqueológica en el solar de la c/ Forner y Segarra, n. ${ }^{\circ}$ 27. Espacio de uso doméstico-industrial", Excavaciones Arqueológicas en Mérida 1997, Memoria 3, pp. 161-220.

- (2000): "Intervención arqueológica en el solar de la c/ John Lennon, n. ${ }^{\circ}$ 28. Hallazgo de un foso de época almohade en torno a la alcazaba árabe", Excavaciones Arqueológicas en Mérida 1998, Memoria 4, pp. 161-220.

- (2001a): "Estructuras domésticas con posible instalación industrial. Intervención arqueológica en el solar no 59 de la c/ Calvario". Excavaciones Arqueológicas en Mérida 1999, Memoria 5, pp. 121-138.

- (2001b): "Estructuras arqueológicas junto al foro de la Colonia emeritense. Intervención arqueológica realizada en el solar sito en la c/ Romero Leal
11". Excavaciones Arqueológicas en Mérida 2003, Memoria 9, pp. 169-192.

- (2002): "Ocupación industrial y funeraria de un espacio suburbano en la Colonia Augusta Emerita. Intervención arqueológica realizada en un solar de la c/ Tomás Romero de Castilla s/n", Mérida. Excavaciones Arqueológicas, 2000. Memoria 6, pp. 79-92.

- (2004): "Secuencia ocupacional de un espacio extramuros de la Colonia Augusta Emerita. Intervención arqueológica realizada en el solar n. ${ }^{\circ} 44$ de la c/ Augusto", Mérida. Excavaciones Arqueológicas, 2001. Memoria 7, pp. 159-208.

- (2005): "De la domus altoimperial al moderno hospital de San Juan de Dios. Intervención arqueológica realizada por la construcción del nuevo hemiciclo de la Asamblea de Extremadura de Mérida", Mérida. Excavaciones Arqueológicas, 2002. Memoria 8, pp. 131-158.

Pızzo, A. (2010): Las técnicas constructivas de la arquitectura pública de Augusta Emerita. Anejos Español de Arqueología, LVI. Madrid: CSIC.

Pryce, J. (2006): "Mould-blown and impreses designs and names on vessels in Spain". En VV. AA.: Corpus des signatures et marques sur verres antiques, vol. 2 . Aix en Provence: AFAV.

Puybaret, M. P.; Borgard, P. y Zerubia, R. (2009): "Teindre comme à Pompéi: approche expérimentale". En Alfaro, C. y Karali, L.: Purpureae Vestes II. Textiles y tintes del Mediterráneo en época romana. Valencia, pp. 185-195.

Rodríguez Hidalgo, S. y Feijoo, S. (2007): "La evolución urbanística de un espacio doméstico extramuros de Augusta Emerita. Intervención en el solar sito en el n. 27 de la Calle Vespasiano", Mérida. Excavaciones Arqueológicas, 2004. Memoria 10, pp. 121-131.

Rodríguez Martín, G. (1996): Materiales de un alfar emeritense: paredes finas, lucernas, sigillatas y terracotas. Cuadernos Emeritenses, 11. Mérida: MNAR.

- (2002): Lucernas romanas del Museo Nacional de Arte Romano. Monografías Emeritenses, 7. Mérida.

SÁNChez BARRERO, P. D. (2000): "Trabajo desarrollado por el Equipo de Seguimiento de Obras durante el año 1998", Mérida. Excavaciones Arqueológicas, 1998. Memoria 4, pp. 413-463.

- (2006): "Trabajo desarrollado por el Equipo de Seguimiento de Obras durante el año 2003", Mérida. Excavaciones Arqueológicas, 2003. Memoria 9, pp. 409-425.

- (2007a): "Trabajo desarrollado por el Equipo de Seguimiento de Obras durante el año 1999", Mérida. Excavaciones Arqueológicas, 1999. Memoria 5, pp. 295-306. 
- (2007b): "Nuevos datos sobre el área funeraria en torno a la vía Caesarangusta en las proximidades de Augusta Emerita. Intervención arqueológica en un solar de la Avda. Juan Carlos I", Mérida. Excavaciones Arqueológicas, 2004. Memoria 10, pp. 103-113.

Sánchez Barrero, P. D. y Alba, M. (1998a): "Intervención arqueológica en el vial c/ Anas. Restos de una instalación agrícola e industrial en el área suburbana de Augusta Emerita", Mérida. Excavaciones Arqueológicas, 1996. Memoria 2, pp. 211-237.

- (1998b): "Intervención arqueológica en la parcela C-1 de Bodegones. Instalación industrial de material constructivo cerámico para la edificación de Augusta Emerita", Mérida. Excavaciones Arqueológicas, 1996. Memoria 2, pp. 211-237.

SÁNCHEZ SÁnCHEZ, G. (1999a): "Intervención arqueológica en el solar de $\mathrm{c}$ Cárdenas n. ${ }^{\circ} 5$. Arquitectura próxima al foro", Mérida. Excavaciones Arqueológicas, 1997. Memoria 3, pp. 93-108.

- (1999b): "Intervención arqueológica en el solar de c/ Hernán Cortés n. ${ }^{0} 12$. Restos de arquitectura doméstica al S.E. del Foro Municipal", Mérida. Excavaciones Arqueológicas, 1997. Memoria 3, pp. 93-108.

- (1999c): "Intervención arqueológica en el solar de la c/ Guardia Civil 10, c/ Vía Ensanche. Nuevas aportaciones al conocimiento del Cerro de San Albín”, Mérida. Excavaciones Arqueológicas, 1997. Memoria 3, pp. 93-108.
SAQUETE, J. C. (2001): "Fistula aquariae con sellos halladas en Augusta Emerita", Anas, 14, pp. 119-170.

Serrá RAFOlS, J. C. (1952): La villa romana de La Cocosa. Badajoz.

Silva Cordero, A. (2005): "Hallazgos arqueológicos puntuales en el valle del Albarregas (Mérida). Seguimiento arqueológico de obra durante los trabajos de encauzamiento del río Albarregas", Mérida. Excavaciones Arqueológicas, 2003. Memoria 9, pp. 411-430.

Silva Cordero, A. y Sánchez Sánchez, G. (2006): "La evolución urbanística de un espacio extramuros al norte de Augusta Emerita. Intervención arqueológica realizada en el solar n. 43 de la C/ Muza (Mérida)", Mérida. Excavaciones Arqueológicas, 2003. Memoria 9, pp. 61-84.

VV. AA. (2003): Atlas antroponimico de la Lusitania romana. Mérida-Bordeaux.

- Dpto. Documentación del Consorcio (2006a): "Intervención arqueológica realizada en la C/ Francisco de Almarza n. ${ }^{\circ}$ 30", Mérida. Excavaciones Arqueológicas, 2003. Memoria 9, pp. 85-90.

- Dpto. Documentación del Consorcio (2006b): "Intervención arqueológica realizada en la C/ Castelar, n. ${ }^{\circ}$ ", Mérida. Excavaciones Arqueológicas, 2003. Memoria 9, pp. 125-151.

- Dpto. Documentación del Consorcio (2006c): "Intervención arqueológica realizada en la $\mathrm{C} /$ Castelar, n. ${ }^{\circ} 1$ esquina con la C/ del Puente", Mérida. Excavaciones Arqueológicas, 2003. Memoria 9, pp. 193-196. 